\title{
La participación en Gabriel Marcel
}

(Continuación)

\section{TERCER NIVEL DE PARTICIPACION EN EL SER: EXIGENCIA ONTOLOGICA, TRANSCENDENCIA Y ESPERANZA.}

Cuando Paul Ricoeur quiso profundizar en la esencia del pensamiento de Marcel y de Jaspers, subrayó que la filosofía de Marcel es "una filosofía de la presencia, una filosofía de la fe y una filosofía de la participación" ${ }^{177 .}$

Entiende que el pensamiento de Marcel se centra en la participación, que resultaría más prioritaria que el tema de la libertad.

La participación significa bajar a las profundidades de la existencia corporal y de la 'esperanza transcendente'. "Sin la Transcendencia yo no sería yo mismo" ${ }^{178}$. Transcender es lo mismo que ir a la búsqueda del Ser a través de los seres.

Mi finitud me convierte necesariamente en un "itinerante". Sólo me comunico realmente conmigo mismo en la media en que me comunico con el otro. Por lo tanto, la metafísica del ser se transforma en una metafísica del 'somos', opuesta a la metafísica del 'yo pienso'.

Marcel marca claras diferencias con Descartes, al tiempo que repudia la tentación idealista.

No obstante, Marcel no identifica ser e intersubjetividad como hace Merleau-Ponty en ocasiones. Esta proposición, tomada al pie de la letra, no se puede sostener. No obstante se puede decir que se acerca mucho a la verdad. La intersubjetividad sintoniza con una comunión profunda enraizada en lo ontológico. Yo no consigo ser sino en la medida en que tomo conciencia de la unidad que me liga con los otros seres y busco un camino, una comunicación más auténtica con ellos: "Yo diría que ellos son ante todo mis compañeros de viaje, o para utilizar el término inglés: my fellow-creatures" ${ }^{179}$.

La verdadera intersubjetividad implica transcendencia, camino hacia la luz, cohabitar con la luz.

177 Ricoeur, P., Gabriel Marcel et Karl Jaspers. Philosophie du mystère et philosophie du paradoxe. Eds. du Temps présent. Paris 1947, 26.

178 Ib., 34.

179 Marcel, G., El Misterio del Ser, 20. 
"Me demander s'il existe un être qui perçoit mon appel et est à même d'y répondre, c'est me placer sur le plan de l'hypothèse, c'est me référer à une constatation, à une vérification idéalement possible. Mais il est clair que si 'par miracle' j'étais en état d'accomplir cette vérification -comme dans le cas où je chercherais à savoir si un S.O.S. lancé par un navire en perdition a été capté par quelque station repérable dans l'espace-, il est manifeste, disje, que cet Autre, que ce Récepteur empiriquement identifié m'apparaître aussitôt comme n'état pas et ne pouvant être le Recours absolu vers lequel monte mon invocation. La transcendance de Celui que j'invoque s'affirme par rapport à toute expérience possible, ou même à toute supputation rationnelle qui ne serait encore que de l'expérience anticipée et schématisée" ${ }^{180}$.

El ser es un don que se recibe; pero para recibir este don es necesaria una 'actividad libre', es decir disponibilidad y amor. Cometería un grave error si pensase que este don me lo puedo conceder a mí mismo. Debo estar disponible, pero eso no es suficiente; la gracia es la que opera realmente sobre mi campo de disponibilidad. El don trae una luz que yo no poseo, porque ese don es la luz.

Cuando Marcel dice "lo esencial del ser consiste precisamente en no ser dado ni a otro ni a él mismo" 181, la palabra 'donné' no quiere significar que el ser en el hombre no sea el resultado de un don; 'donné' significa, en este caso, que el ser no es algo arrojado como un objeto delante de un sujeto.

Marcel acude al significado de la hospitalidad para clarificar sus puntos de vista: La hospitalidad no existe para llenar un vacío con personas extrañas, sino para invitar al otro a participar de una cierta plenitud.

Cuando se trata del don del ser, el hecho de recibirlo implica también la capacidad y voluntad de dar, de darse. Ocurriría lo mismo al ejecutar una partitura musical: el intérprete participa, en cierto modo, de la inspiración misma del compositor.

El ser recibido es, a su vez, donante, creador de unidad y de comunión en el amor.

Esta unidad no quiere decir identidad de pensamiento o de gustos, consiste más bien en reconocer las peculiaridades del otro, y amarlo incluso por esas mismas diferencias y peculiaridades.

Cuando Marcel trata de explicarnos la plenitud del ser y la participación en este ser, utiliza, con cierta frecuencia, las metáforas de la luz y de la música.

180 Marcel, G., Du Refus à l'Invocation, Gallimard 1940,189.

181 MARCEL, G. Etre et Avoir, 65. 
Reconoce en El misterio del Ser que "tiene una predilección invencible por las comparaciones musicales" 182 .

López Quintás, buen conocedor de la filosofía de Marcel, en su artículo "La experiencia estética musical y el pensamiento filosófico de Gabriel Marcel" ${ }^{183}$, analiza las posibilidades de la metáfora musical.

Recuerda que Marcel se ha definido como "un hombre a la escucha", "un ser atento a los diversos modos y planos de la realidad que puede captar el oído interior" 184.

Según López Quintás, el oído capta respetuosamentene, a distancia, globalmente; se recrea reviviendo la música percibida, oída.

Desde niño, la música constituyó para él una fuente de placeres espirituales y un camino para ir más allá de lo visible. La música le permitió comprender la 'armonía de los contrarios', la armonía de lo diverso, de lo diferencial. Elementos diferentes componen una sinfonía, dialogan entre sí, se complementan, se 'comunican'.

"En su infancia, Marcel tuvo ocasión de abrirse muy pronto al mundo de la gran música. Comienza a deletrear en el piano algunas sonatas de Mozart y de Beethoven, se sobrecoge al oir a Alfred Bachelet descubrir el secreto de la Tetralogía y el Parsifal wagnerianos, se adentra sorprendido en los preludios de Bach, vive como destinado a él mismo el hondo mensaje de dolor que contienen los Adagios beethovenianos de la Patética y la Apassionata. Para el niño retraído y solitario, que era él entonces, este adentramiento en el mundo de la música constituyó la única forma de exadirse un tanto de la vida cotidiana" ${ }^{185}$

Insiste Marcel en considerar la música como una forma de comunión, recordando que le proporcionaba una 'seguridad misteriosa' a él que había sido educado en el agnosticismo.

"No es extraño, -comenta López Quintás-, que toda la investigación filosófica de Marcel haya sido iluminada constantemente por la experiencia musical en sus diversas formas o momentos -creación, interpretación, lectura de partituras, improvisación-. Esta vinculación nutricia de ambos tipos de experiencia -la musical y la filosófica- explica que la producción entera de Marcel y su vida misma hallen un punto de concentración e iluminación en

182 Marcel,G., El Misterio del Ser, 188

183 Lopez Quintas, A., en Gabriel Marcel 1889-1989, n 109 de Estudios Filosóficos, dedicado monográficamente a G. Marcel

184 Ib., 483

185 Ib., 484 
estas dos frases: "La música es, en cierta medida, la patria del alma", "El ser es el lugar de la fidelidad" ${ }^{186}$.

Tal y como dice Marcel, en Etre et Avoir, el artista y la creación no se mueven en el ámbito del tener, sino en el terreno del ser:"Tan pronto como hay creación, en cualquier grado que sea, estamos en la esfera del ser" ${ }^{187}$. De igual manera, comenta K.T. Gallagher, carece realmente de sentido el hecho de utilizar la palabra "ser", sino nos encontramos en el ámbito de la creación.

La creatividad es un mensaje auténtico. Llega al público por encima de las dificultades del lenguaje y la creatividad muestra coincidencias con la autenticidad de un lenguaje.

López Quintás recoge trece cuestiones importantes que Marcel ha madurado a la luz de la experiencia musical:

$1^{\text {a }}$.- El concepto de 'presencia' como algo no objetivo, no objeto, algo que supera el esquema dentro-fuera.

$2^{\mathrm{a}}$.- La distinción entre el ser y el tener. Sólo las actitudes creativas o comunicativas se sitúan en la esfera del ser.

$3^{\mathrm{a}}$.- En el orden del ser, surge la intercomunicación, el 'entreveramiento de ámbitos de vida',la apertura, el compromiso, el sentido de la responsabilidad.

$4^{\mathrm{a}}$.- "Esta trama de apelaciones y respuestas da lugar a las experiencias 'reversibles', que no son vertebradas por los esquemas acción-pasión, subjeto-objeto, sino por los esquemas yo-tú, apelación" 188 .

$5^{\mathrm{a}}$.- La interpretación musical evoca la fidelidad sin cerrar el camino a la transcendencia. Supera el esquema inmanencia-transcendencia.

$6^{\mathrm{a}}$.- La fidelidad requiere 'un lenguaje dinámico', una realidad dinámica. En La dignidad humana, Marcel afirma que vivir en la luz de la fidelidad es progresar en una dirección que es la misma del ser; se puede entonces comprender que el ser fiel se halla, por ello, como en ruta hacia un ser más, en oposición a quien, por el contrario se dispersa en sentimientos inconsistentes $\mathrm{y}$ en acciones incoherentes.

$7^{\text {a }}$.- En el encuentro se superan los fanatismos, al tiempo que buscamos la verdad y la comprensión.

8a .- y $9^{a}$.- La esperanza 'abre un crédito de confianza', con carácter colectivo.

186 Ib., 485-486

187 MARCEL, G., Etre et Avoir,218

188 LOPEZ QUINTAS, A., La experiencia estético musical, 509 
$10^{\mathrm{a}}$.- La actitud de apertura permite caer en la cuenta "de que está participando en realidades muy elevadas y fecundas que lo superan y ensanchan".

11.- "El campo de juego y encuentro" en que el hombre se realiza como persona es el de la comunidad. La comunidad tiene características de inmanencia y de trascendencia como ocurre en una composición musical.

12. . - Las metáforas musicales, más que metáforas son experiencias similares a las que analiza la filosofía, ya que la investigación filosófica es "una lenta y progresiva orquestación de un cierto número de temas inicialmente dados"."La música ha sido para mi, en el curso de esta búsqueda filosófica agotadora que ha sido la mía, como un testimonio permanente de esta realidad que me esforzaba por alcanzar a través de los áridos caminos de la reflexión pura".

$13^{\mathrm{a}}$.- Considera Marcel que la experiencia musical le permitió conceder a los diversos modos de experiencia el debido 'peso ontológico', el nivel pertinente de participación en el ser.

Marcel distingue entre 'exigencia de ser', 'la llamada del ser' y 'el ser como plenitud'. El ser es el fin hacia el que caminamos, como diría un personaje de su teatro, pero que dicho fin lo vemos y no lo vemos.

Fernando Vela en su crítica al libro de Feliciano Blázquez dice lo siguiente: "Feliciano Blázquez Carmona, Catedrático de Filosofía...es uno de los españoles que conoce a fondo el pensamiento de Gabriel Marcel, su vida y su espíritu. Tuvo con él trato directo y mereció su amistad. Frecuentó sus obras, y en 1982 presentó este tema -La filosofía de Gabriel Marcel-como tesis doctoral en la Universidad Complutense. ...La obra que edita Ediciones Encuentro es 'reelaboración' de su tesis".

De dicha tesis -muy valiosa-, interesa especialmente el apartado que dedica a la "Ontología de la invocación".

Señala que "la reflexión segunda o a la segunda potencia también se sirve de meditaciones conceptuales, -'de un modo general hacer algo inteligible es conceptualizarlo'-, pues de lo contrario, no habría filosofía. Sólo que no materializa los conceptos como hace la reflexión primera, ni los abstrae de la existencia; no traduce en términos de tener lo que es un modo de ser" ${ }^{189}$.

Reconoce Blázquez que resulta difícil expresar en lenguaje racional las sutiles relaciones que traduce la palabra experiencia o el término participación. Como dice Marcel en El Diario Metafísico, la participación real no deja

189 Blazquez Carmona, F., Gabriel Marcel: Del existente concreto al Tú Absoluto. Tesis Doctoral presentada en 1982 en la Universidad Complutense de Madrid. Supone una contribución notable al conocimiento de la filosofía de Marcel y de la Bibliografía sobre este autor. 
traducirse al lenguaje objetivo, pues ésta se encuentra más allá de lo que se ve, 'está ligada al ser'.

"Una filosofía de lo concreto, existencial, pretende situarse en el corazón de la existencia, que no es un dato, ni un objeto, no es una realidad ya hecha, sino vocación de ser, libertad situada, misterio en el que estamos comprometidos" 190 .

La filosofía debe situarse en un campo participativo y concreto, en contraposición a las ciencias que prefieren un terreno objetivista y generalizante.

\section{a.- Exigencia ontológica y transcendencia:}

Marcel pretende elaborar una filosofía del ser, del misterio y de la transcendencia. No quiso hacer un religión, como algunos injustificadamente le ha reprochado.

"Esto es fundamental en mi pensamiento, -asegura Marcel-, el misterio; no es interpretado como lo es entre los agnósticos, como una laguna en el conocer, como un vacío que hay que llenar, sino, por el contrario, como una plenitud; diré más: como la expresión de una voluntad, de una exigencia tan profunda que no se conoce a sí misma, que se traiciona sin cesar forjándose falsas certezas, todo un saber ilusorio, con el que sin embargo no puede contentarse, y que ella misma rompe al prolongar el impulso al cual ha cedido para inventarlas. En este reconocimiento el misterio se transciende" ${ }^{191 .}$

Este impulso hacia la transcendencia, este apetito de conocer, -añade Marcel-, está en la raíz de nuestra grandeza. Aristóteles, desde sus perspectivas, también había señalado que todo hombre tiene, por naturaleza, el deseo de saber.

Al propio tiempo el misterio revela nuestra finitud, nuestra limitación para conocer. El misterio nos avoca a una 'humildad ontológica', a la 'confianza en el ser': "El misterio consiste en el hecho de insertarme en algo que me transciende infinitamente" 192

Por eso las preguntas se repiten incesantemente intentando llegar un poco más allá: "Il faut voir:

1.- Que l'exigence ontologique en cherchant à ser comprendre ellemême découvre qu'elle n'est pas assimilable à une recherche de solution;

2.- Que le métaproblématique, c'est une participation qui fonde ma réalité de sujet (nous ne sommes pas à nous-mêmes); et la réflexion montre

190 Ib., 375

191 MARCEL, G., Du Refus à l'Invocation, 198

192 MARCEL, G., El Misterio del Ser, 256 
qu'une semblable participation, si elle est réele, ne peut pas être une solution, sans quoi elle cesserait d'être une participation à une réalité transcendante pour devenir (en se dégradant) insertion effective.

Donc il faut ici próceder à deux examens distints dont l'un prépare l'autre sans le conditionner et qui tendent en quelque sorte l'un vers l'autre:

a) Investigation portant sur la nature de l'exigence ontologique;

b) Investigation portant sur les conditions dans lesquelles pourrait être pensée une participation supposée réelle; on découvre alors que précisément cette participation dépasse l'ordre de problématique, de ce qui peut être comme probléme" ${ }^{193}$.

Realidades como Dios, el ser, el amor,la justicia, la muerte, la esperanza, resultan de difícil o imposible definición, porque intentar definirlas equivale a transformar un problema en un misterio:

"Siempre que hay un encuentro con el ser, hay un misterio. Mi cuerpo en cuanto mío, -no como algo que tengo, sino en cuanto soy mi cuerpo-, no puede ser expresado en categorías problemáticas. El mundo tampoco es objetivable, puesto que todo juicio sobre el mundo, es calificado mediante mi participación en el mundo" 194.

En El Misterio del Ser, Marcel insiste en que el ser se nos manifiesta como una presencia misterosa, que sólo podemos alcanzar mediante la profundización de nuestra propia experiencia.

El ser no es un objeto dispuesto para la inspección. No podemos inspeccionar el ser. El ser no es un puro dato, un puro objeto, es una realidad que me incluye a mí que pregunto por el ser.

Marcel utilizaba el término misterio antes de su conversión, por lo tanto no pretende significar una verdad revelada, sino mostrar que tiene 'una dimensión ontológica'.

En la segunda parte del Diario Metafísico, Marcel nos habla del 'misterio ontológico'. La cuestión filosófica de primera magnitud, consiste en la apertura hacia el misterio renovado del ser, algo 'inagotable concreto'. Esta apertura da sentido y profundidad a nuestra existencia.

En este sentido Marcel redobla sus esfuerzos para elaborar una filosofía del misterio, de la transcendencia y del ser: "Les approches concrètes du mystère ontologique devront ètre cherches non point dans le registre de la pensée logique dont 'objectivation soulève una question préalable, mais plutôt dans l'élucidation de certaines données proprement spirituelles, telles

193 MARCEL,G., Etre et Avoir,165

194 Blazquez Carmona, F., La filosofía de Gabriel Marcel. Tesis Doctoral, 360 
que la fidélité, l'espérance, l'amour, ou l'homme nous apparaît aus prises avec la tentation du reniement, du repliement sur soi, du durcissement intérieur, sans que le pur métaphysicien soit en mesure de décider si le principe de ces tentations réside dans la nature elle-même considérée dans ses caractérístiques intrinsèques et invariables... Peut être, sur le plan ontologique, est-ce la fidélité qui importe le plus. Elle est en effet la reconnaissance, non pas théorique ou verbale, mais effective, d'un certain permanent ontologique, d'un permanente qui dure et par rapport auquel nous durons, d'un permanent qui implique ou exige une historie, par opposition à la permanence inerte ou formelle d'un témoignage qui à chaque moment pourrait être oblitéré et renié. Elle est une attestation non seulement perpetuée, mais créatrice, et d'autat plus créatrice que la valeur ontologique de ce qu'elle atteste este plus éminente" ${ }^{195}$.

En 1958 Marcel confiesa que la reflexión sobre el ser se encuentra en el centro de su pensamiento, y parte de esta reflexión se traduce en la distinción de problema y misterio.

Esta distinción debe ser una especie de 'canal intelectual' abierto a la navegación reflexiva y espiritual.

"Todo el empeño de la filosofía de Gabriel Marcel consiste precisamente en tomar contacto con lo concreto, con ese mundo de realidades profundas más allá de las representaciones conceptuales, en hacer más comprensiva la idea de razón...La Metafísica, pues, no puede tratar de resolver el misterio, degradándolo en problema, sino reconociéndolo, reverenciándolo. En el misterio ontológico el plano de la constatación es superado por el de la absoluta invocación, que carecería de sentido sin la presencia del Invocado Acertadamente. Gabriel Marcel definió su filosofía como "una filosofía de la participación" ${ }^{196 .}$

Feliciano Blázquez también considera la participación tema central en la filosofía de Marcel. Señala que Marcel desemboca en la dialéctica de la participación, porque sólo la participación permite superar la actitud de espectador para entrar en una comunicación-comunión-activa con los demás.

Troisfontaines había advertido que el "atisbo de lo transcendente" aparece al final de casi todos los temas centrales en el pensamiento de Marcel.

Este hecho, confiesa Fernando Vela, responde a una convicción ontológica, metafísica, si se quiere: el yo, el tú y todo el entorno, cl entorno natural

195 MARCEL, G., Etre et Avoir, 172-173

196 Blazquez Carmona, F., Del existente concreto al Tú Absoluto. Tesis Doctoral, 350 
e histórico de lo humano son participaciones, teofanías, de un ser cuya entidad no queda agotada en ninguna de sus realizaciones objetivas, de un ser que transciende todo lo dado y que, en último extremo, es para Marcel un ser personal ${ }^{197}$.

Mi experiencia, la comunión que establezco con los otros, la fidelidad que les otorgo, son en el fondo una 'invocación a un Tú Absoluto', que 'ordena a lo eterno' todo lo existente, y que le concede un 'plus de ser', revelando los sentidos más íntimos y profundos.

El significado de la 'dimensión transcendente' del ser, lo abordó Marcel en una conferencia pronunciada en la Universidad de Aberdeen, que lleva por título: "La exigencia de Transcendencia". Transcender no significa sobrepasar, sinó mas bien profundizar "-profundidad transhistórica de la historia"-, llegar a esas realidades últimas que dan sentido a la vida.

Hay que "reconocer que, en tanto que no somos cosas, en tanto que rehusamos reducirnos a la condición de cosas, pertenecemos a una dimensión enteramente distinta del mundo, a una dimensión que puede y debe llamarse supratemporal... Debemos reconocer que por encima de nosotros existe una realidad viva, sin duda incomparablemente más viva que la nuestra, y a la que pertenecemos..." 198 .

Prometer fidelidad a otro es ir más allá de la experiencia superficial, es transcender la experiencia superficial para llegar a una experiencia más profunda, a una presencia, a una comunión. Prometer fidelidad es ir más allá del cansancio de la rutina superficial, de la desilusión o de la pura sospecha.

En el fondo, dirá Marcel,"Dios es la razón suficiente de la fidelidad" ${ }^{199}$. La fidelidad, con Dios como garante, vendría a ser un reconocimiento de la "permanencia ontológica".

Una ética de la fidelidad tendrá que fundamentarse en algo más perenne que lo puramente humano, en el eco de la llamada que en nosotros deja el Tú Absoluto, en la exigencia de ir al encuentro de este Absoluto, garante firme de la fidelidad.

La fidelidad es un testimonio, algo que parece avalar más allá de los sentimientos cambiantes de los humanos. La fidelidad permanece como una testificación ante notario, como un cerro testigo.

197 VELA, F.,"Raíz ontológica y Vertientes existenciales de la fidelidad en G.Marcel", Estudios Filoś́ficos 109(1989) 555.

198 MARCEL,G., El Misterio del Ser, 317-318.

199 MARCEL, G., Homo Viator, 210. 
La fortaleza de este testimonio hunde sus raíces en el compromiso humano, pero también en la exigencia de comunión hacia un Ser Absolutamente fiable e invariable, y por lo tanto, garante.

Marcel rechaza el idealismo porque entiende que en él hay una falta de "humildad ontológica". Prefiere un realismo de lo concreto, un "nuevo realismo". Frente al idealismo, la intersubjetividad y la comunión.

"Esta resistencia incoercible corresponde a la seguridad, que no sé si llamar maciza, que implican algunas de las más altas experiencias humanas, sea la aprehensión, sea al menos la posición de algo que va más allá de toda verificación posible: para fijar las ideas, evocaré simplemente el amor o la adoración cuyo objeto es por definición imposible de detallar, y no se deja alcanzar gradualmente por pasos en que, por el contrario, se divide todo proceso de verificación" ${ }^{200}$.

Se puede decir que hay terrenos en los que se producen condiciones 'inespecificables' porque son inherentes al sujeto mismo en tanto que experiencia 'viviente', la cual por su propia esencia no puede 'reflexionarse' a sí misma, al menos en su totalidad.

"Lo que me aproxima a un ser, lo que me une efectivamente a él...es más bien pensar que él ha atravesado como yo ciertas pruebas, que está sometido a las mismas vicisitudes..., que ha sido amado, que otros seres se han inclinado sobre él y han esperado en él" ${ }^{201}$.

La conversión de Marcel al cristianismo no supuso ninguna panacea que le resolviese todos los problemas filosóficos; tampoco supuso una ruptura con el pensamiento anterior. Significó, si acaso, una culminación de un proceso, una 'marcha hacia la luz', un intento de profundizar en el misterio. La conversión era el resultado de su itinerario, de su búsqueda.

No obstante, sí significó, probablemente, el final de la etapa idealista y la reacción para superarla. El segundo Journal lo titula Etre et Avoir, que inauguraría el 'realismo cristiano', la filosofía concreta abierta a la transcendencia.

Cuando nosotros estamos humildemente disponibles, es el misterio, el Tú el que nos descubre a nosotros, el que sale a nuestro encuentro.

"El misterio es lo que reune", lo que nos permite respirar y crecer: "lo metaproblemático es una participación que fundamenta mi realidad de sujeto" ${ }^{202}$.

200 MARCEL,G. Du Refus à l'Invocation, Introducción.

201 Ib.,.

202 Ib., 71 
Lo misterioso, más que una idea abstracta, es una presencia, que cohabita con la fidelidad, que se relaciona con la exigencia ontológica.

En el catolicismo encontró Marcel un clima apropiado para la intersubjetividad, para el encuentro. Nuestro autor nos recuerda siempre que hay una comunión de pecadores de la misma manera que la Iglesia dice que hay una "comunión de los Santos".

La salvación, -confiesa-, será más un camino, una comunión, que un estado.

"Si la salvación se confunde en un sentido con la paz, se trata de una paz viviente y de ninguna manera de una inmovilización por la cual nuestro ser se congelaría en la contemplación de un astro fijo. Pero, ¿qué será esta paz viviente sino un progreso en la verdad y en el amor, es decir, en la consolidación de una ciudad inteligible que es al mismo tiempo y en primer lugar una ciudad de almas, una ciudad del amor?. A este respecto la idea cristiana de un cuerpo místico "es, quizá, la que presenta mayor interés para el filósofo" 203.

Ciertamente la ontología de Marcel estaba orientada hacia la revelación. Si bien es la revelación misma la que irradia hacia mí, de una manera fecunda, sin que uno acierte a explicarla en detalle, aunque sí deba aceptarla o estar dispuesto para su aceptación.

"A mis ojos al menos, -explica Marcel-, una filosofía concreta no puede dejar de ser imantada, acaso sin saberlo, por los datos cristianos. Creo que esto no podrá escandalizar. Para un cristiano existe una conformidad esencial entre el cristianismo y la naturaleza humana. Por lo tanto, cuanto más profundicemos en la naturaleza humana, tanto más nos colocaremos en el eje de las grandes verdades cristianas" 204.

Marcel dice lo siguiente: "El filósofo que ha llegado a la exigencia de transcendencia en su plenitud, es decir, que no puede satisfacerse ni con lo que hay en el mundo ni aun con el mundo mismo considerado en su totalidad -totalidad, por otra parte, siempre ficticia-, puede muy bien, sin embargo, permanecer fuera de toda conversión a una religión histórica determinada. No hay allí ningún pasaje necesario... Todo lo que puede decirse es que en su límite extremo el pensamiento metafísico percibe la posibilidad de la conversión, ...se dará uno cuenta con bastante exactitud de lo que fue mi preocupación metafísica central y constante, si digo que se trataba para mí de descubrir cómo el sujeto, en su misma condición de sujeto, se articula a una realidad que deja, desde este punto de vista, de poderse representar

203 MARCEL, G., El Misterio del Ser, 94

204 Marcel, G., Du Refus à l'Invocation, 95 
como objeto sin dejar, por eso de ser a la vez exigida y reconocida como realidad.

Tales investigaciones solamente eran posibles a condición de superar un psicologismo que se limita a definir y caracterizar actitudes sin tomar en consideración su orientación, su intencionalidad concreta. De este modo, aparece la convergencia absoluta de lo metafísico y de lo religioso, que se manifiesta desde mis primeros escritos. Señalemos una vez más cómo se justifica esa convergencia desde el punto de vista que hice mío ya en el primer Journal Métaphysique. Lo que tendía a excluir de mis sondeos era la noción de un pensamiento que definiese en cierto modo objetivamente la estructura real y. se considerase desde entonces calificado para decidir sobre ella. Yo proponía, por el contrario, que la empresa, en principio, no podría llevarse a cabo más que dentro de una realidad frente a la que el filósofo no puede nunca colocarse como se instala alguién frente a un cuadro para contemplarlo. Por eso, toda mi investigación era un anticipo de la posición del misterio, tal como he precisado en Positions et Approches concrètes du Mystère Ontologique" ${ }^{205}$.

Para K.T. Gallagher, el tercer nivel de participación está definido por el ser o la plenitud, y no hay duda de que el misterio del ser es, en este sentido, lo que interesa en última instancia a la reflexión filosófica.

La afirmación fundamental para un filósofo 'el ser es', será una 'verdad dicha por y a mi libertad'.

Para Marcel el problema del ser vendrá a convertirse, en realidad, en el misterio del ser.

El misterio del ser comienza con el consentimiento al ser y termina cuando aceptamos el tener como modo predilecto de existencia. Hay una relación clara entre misterio y valor. Sólo puede ser misterioso aquello que tiene un valor para mí, que es susceptible de interesarme.

Además de tener un valor, debe existir en relación con el mundo del tú, del otro, que entra en comunión conmigo: No hay misterio posible sino en el orden del tú.

En el misterio estoy comprometido, debido a que el misterio es algo reconocido o a reconocer, también puedo negarlo activamente y situarme en el camino propio de un objeto: el objeto excluye todo misterio.

“C'est que la conscience du sujet s'accompagne constantment de l'exigence de l'intersubjectivité" ${ }^{206}$. El sujeto, el tú, implica misterio, intersubjetividad; el objeto, por el contrario, excluye ambos términos.

205 MARCEL, G. Regard en Arrière. En L'Existentialisme chretien. Plon, Paris 1946, 318.

206 GotTIER, G., Un hommage à Gabriel Marcel, Revue de Métaphysique et de Morale, 3 (1975) 323. 
La fidelidad "es una perpetuación activa de la presencia", y por esto mismo la fidelidad es creadora. Según K. T. Gallagher, y como ya hemos apuntado, yo no doy un yo que ya tengo, sino un yo que adquiero dándolo. Mediante la fidelidad transciendo mi devenir y alcanzo mi ser. Pero el ser que alcanzo no es un ser que estaba ya ahí; sólo está ahí en la medida en que yo lo alcanzo. Es decir, el ser que revela la fidelidad, crea. Cuando Marcel escribe 'fidelidad creadora', no ha perdido las riendas de su lenguaje, como ya hemos observado repetidamente. Quiere decir eso literalmente. La fidelidad crea el yo, el yo como no-objeto. La fidelidad es distinta de la constancia. Para que pueda darse fidelidad, se tiene que dar intersubjetividad y creatividad.

Bochenski afirma que Marcel considera su tesis de la esperanza como la más importante de su obra. La ésperanza, explica Marcel, se emparenta con la vida, no en sus manifestaciones, sino en su esencia, que es quizás, cierta perennidad, según ya hemos visto.

El misterio nos sumerge en el mundo del tú, y es el Tú el que nos da la esperanza, por encima de la muerte, porque abrirse al tú para establecer presencia, intersubjetividad o fidelidad en él, es amarlo y, como bien sabemos, "amar es decir al otro: tú no morirás". Cuando alguien ama a otro, se asienta en la fidelidad, se asienta en el ser; si le es fiel, no desaparecerá totalmente. Si pues, el misterio, la fidelidad y el amor son el asiento de la esperanza. Y la esperanza, como dice Bochenski, posee un peso ontológico: muestra que el triunfo de la muerte en el mundo no es más que aparente y nada último.

Para que exista intersubjetividad no solo es necesario que se den relaciones entre dos personas (relaciones-tú), sino que es preciso que entre dos personas se dé una presencia. Es necesario que se establezca una comunión entre estas dos personas, produciéndose la atmósfera de misterio.

Cuando se han dado presencia e intersubjetividad, tenemos ya el camino preparado para la aparición de la fidelidad, ya que la fidelidad en palabras del propio Marcel: es una perpetuación activa de la presencia.

Copleston lo describiría así: En el plano de la intersubjetividad, me percato conscientemente de mi participación en el Ser y me lo apropio en el nivel de la comunicación y comunión personales. En este nivel de intersubjetividad mi exigencia del Ser queda satisfecha en parte. En comunión con otro y en la fidelidad hacia otro, transciendo la relación del tener y me encuento en la esfera del Ser.

En Etre et Avoir, Marcel habla del "ser como lugar de la fidelidad". Kenneth T. Gallagher dice que, en cierto momento, esta fórmula adquiere un relieve extraordinario en la conciencia de Marcel, como irresistiblemente sugestiva, como si la verdad en ella contenida fuera la fuente de la que bro- 
tan y a la que vuelven las percepciones de su pensamiento. Y con razón, porque su prolongada meditación sobre las implicaciones ontológicas de la fidelidad servirán fácilmente como paradigma del método filosófico de Marcel. Siguiéndola, llegamos gradualmente a comprender cómo un descenso a la intersubjetividad es simultáneamente un ascenso a la transcendencia.

Como es bien sabido, el caballo de batalla de todo filósofo es la cuestión del ser. En nuestro caso más que del problema del ser, habrá que tratar del misterio del ser.

¿Qué es el ser para Marcel? En El Misterio del Ser hay una conferencia que lleva por título esta misma pregunta: “¿Qué es el ser?”. El mismo escribe que no es su intención internarse en las profundidades de la metafísica aristotélica, o en las doctrinas escolásticas que la han prolongado.

Según Marcel, la pregunta se habrá de formular así: ¿Qué es el ser, y cómo es posible conferirle un sentido inteligible para nosotros?.

La expresión 'para nosotros' tiene en el autor que nos ocupa una relevancia especial. Se inscribe en la línea marceliana de pensamiento, que pugna por transcender el pensamiento en general, para llegar a lo concreto.

La presencia y la inersubjetividad van a estar en la base de la ontología marceliana. Se me preguntará, dice Marcel, si esta intersubjetividad que coloco en la base de la Ontología puede dar lugar a alguna proposición simple y distintamente formulable. Una toma de posición semejante, continúa diciendo, de inmediato pone de relieve el carácter esencialmente anticartesiano de la metafísica hacia la cual vamos a tener que orientarnos. No basta decir que es una metafísica del ser: es una metafísica del somos por oposición a la metafísica del yo pienso; insiste una y otra vez nuestro autor.

El ser no es objetivable, el ser es inexhaustible, être se contrapone a avoir.

Como apéndice a la segunda parte del Diario Metafísico, se publica un artículo titulado: "Esquisse d'une phénoménologie de l'avoir". Lo consideramos importante por sus precisiones en torno al avoir. El avoir tiene relación con lo objetivo, con lo clasificable, con lo que se puede poseer.

$\mathrm{El}$ ser no se puede poseer tal y como poseemos un objeto. El ser se participa. Existen varios niveles de participación en el ser, aunque no es fácil precisar exactamente lo específico de cada nivel y las articulaciones entre ellos.

Kenneth T. Gallagher, quiere dejar bien claro que Marcel discierne tres niveles de participación en el ser: El nivel de la encarnación, que se actualiza por la sensación y la experiencia del cuerpo como mío; el nivel de la comunión, que se actualiza por el amor,la esperanza y la fidelidad, y el nivel de la transcendencia, que se actualiza por la exigencia ontológica,la seguridad primitiva, y la ciega intuición del ser. Creemos que no conviene ser tan tajantes 
en la precisión de niveles, ya que existen continuas articulaciones y relaciones entre los diversos niveles; concretamente, el tercer nivel, creemos que no está adecuadamente precisado. La transcendencia afecta, de alguna forma, a todos los niveles; de lo contrario no habría progreso ni en el ser, ni en el misterio; por otra parte, la fidelidad creadora y la esperanza encontrarían en el tercer nivel toda su eficacia y significado.

En El Misterio del Ser, afirma Marcel: "Me pregunto si la exigencia de transcendencia no coincide en el fondo con la aspiración hacia un modo de experiencia cada vez más puro" ${ }^{207}$. Marcel no opone, sin más, experiencia y transcendencia.

Transcendente no significa ir más allá de la experiencia, ni sobrepasar determinados niveles de presencia o comunión: "Transcendente no puede querer decir transcendente a la experiencia, sino que por el contrario, debe haber una experiencia de lo transcendente" en cuanto tal, y la palabra (trans-cendencia) sólo tiene sentido en estas condiciones" ${ }^{208}$.

"La experiencia de transcendencia, -añade Marcel-, no debe interpretarse en ningún caso como la necesidad de superar la experiencia, pues más allá de la experiencia no hay nada que se deje, no digo pensar, ni siquiere presentir" ${ }^{209}$.

Después de señalar lo que no es la transcendencia, Marcel se arriesga a dar una definición: "La transcendencia consiste en sustituir algunos modos de experiencia por otros" 210 .

"La experiencia aparece ligada a la presencia de algo en mí y para mí, y se interpreta como el acto de replegarse sobre ese algo" ${ }^{211}$.

La expresión "sustituir unos modos de experiencia por otros", creo que aún es obscura. Vamos a ilustrarla con un ejemplo, de Marcel mismo, que ya nos es bien conocido: "pensemos, nos dice, en la transformación interior que puede producirse en el interior de una relación personal. Por ejemplo, un marido que comenzó por considerar a su mujer en relación a sí mismo, a los goces sensuales que podía darle, o simplemente a los servicios que le prestaba como criada sin sueldo. Supongamos que llegue a descubrir que esta mujer tiene una realidad y valor propios, y que insensiblemente comience a tratarla como existente en sí: llegará a ser capaz de sacrificar por ella un gusto o un proyecto que antes parecía tener una importancia incondiciona-

$\begin{array}{ll}207 & \text { MARCEL, G., El Misterio del Ser, } 56 \\ 208 & \text { Ib., } 48 \\ 209 & \text { Ib., } 50 \\ 210 & \text { Ib., } 43 \\ 211 & \text { Ib., } 43\end{array}$


da. Estamos ante un cambio que ilustra directamente la cuestión. Este cambio afecta al centro, digamos más bien que el pensamiento sustituye un centro por otro" 212 .

Se objetará que en este caso la transcendencia designa una 'alteridad absoluta'; pero se deshará la objeción si se recuerda que la "conciencia es conciencia de algo distinto de sí" ${ }^{213}$, y que la transcendencia no es una cabra montés, que vaya saltando de roca en roca sin profundizar, sino que la transcendencia es un puente de unión que se apoya y se tiende entre las personas y sus experiencias profundas.

Por las relaciones-tú transcendemos los tús particulares para llegar al Tú Absoluto: transcendemos la región del 'haber' para llegar a la del 'ser'. Caminamos con los 'seres-tús' hasta llegar al 'Ser' meta última del itinerario existencial" ${ }^{214}$.

Así pues, se puede decir que: Transcendencia es profundizar 'el ser-tú', es decir experimentar el ser con precisión, y después caminar con los 'seres' y por los 'seres' hacia el 'Ser'.

Hay una cita de Lenz, bastante conocida, pero que es muy significativa a este respecto: "Las situaciones-límite de angustia, muerte, suicidio, desesperación y traición ocupan en Marcel un espacio sorprendentemente amplio; y es que tales situaciones representan justamente el punto en el que el pensamiento penetrando en un "De profundis", se abre a la auténtica transcendencia, y se eleva, desde la indiferencia negativa, hasta la invocación del Tú Absoluto" ${ }^{215}$.

Parece ser que desde este ángulo se descubre también la transcendencia. Creo que esta vertiente va unida a la vida misma de Marcel. Este, además de su contextura enfermiza, y de las desgracias personales y familiares, cuenta en su haber con los primera guerra mundial, con la Gran Revolución Rusa, con la crisis económica de mil novecientos veintinueve, y con la segunda guerra mundial. Todo esto le ha hecho meditar profundamente, le ha hecho penetrar en un "De profundis", y buscar lo que realmente diera sentido y fuera capaz de salvar esas situaciones.

Vió que el hombre podía ser destruido. Sintió que "el mundo estaba destrozado". Intuyó que "el suicidio aparece hoy ligado a la condición del mundo humano en su totalidad" ${ }^{216}$. "Términos como libertad y democracia

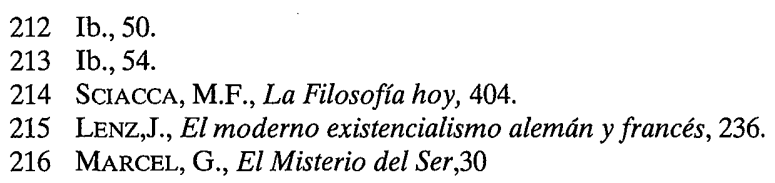


tienden a perder su significación" ${ }^{217}$. "Se usan, además, las palabras abstractas para favorecer la obnubilación de la verdad. La posibilidad de suicido es para él el punto de arranque de toda metafísica auténtica" ${ }^{218}$.

Nadie, a la vista de esto, negará que "el existencialista cristiano" no experimentó profundamente la angustia de las situaciones-límite, y que no aceptó la realidad de las cosas con toda honradez.

Ahora, pues, ¿será capaz de superar la angustia en que está sumida su vida? ¿Por qué esta situación límite exige y necesita ser superada? ¿En qué se apoya Lenz para decir que tales situaciones-límite representan justamente el punto en que el pensamiento se abre a la auténtica transcendencia?

Para Marcel es cierto que el yo (contingente como es) no tiene plenamente sentido en sí mismo y por sí. Mi yo necesita transcenderse a sí mismo e ir hacia los otros yos. El yo tiende a buscar su apoyo, su amor, su inmortalidad en los otros yos (en los tús), y por éstos camina hacia el más perfecto amor, hacia la máxima fidelidad y la máxima garantía de inmortalidad, que es el Tú.

Posiblemente el tú está más plenamente sumido en el misterio cuando está en situaciones-límite, porque se reconoce a sí mísmo con más autenticidad: reconoce que puede sentir la angustia, porque ya la está sintiendo, reconoce que no tiene fuerza para salir de la angustia -si la tuviese saldría-, y reconoce que necesita invocar a otro para que le saque definitivamente de la angustia.

Así pues, el ser angustiado se reconoce como es. Se reconoce plenamente dentro del misterio, porque está completamente comprometido dentro de una situación que él no se explica o no puede resolver. Si recordamos, por otra parte, que todo misterio desemboca en lo eterno, vemos cómo el ser angustiado está en buenas condiciones para transcender hastá su último apoyo y explicación.

“La palabra 'misterio', nos decía Moeller, aparece por primera vez en la terminología marceliana, en la obra L'Iconoclaste de 1919" ${ }^{219}$. Desde este momento la palabra misterio tatuará la obra de Marcel. Su libro más importante se titula: El Misterio del Ser. El misterio vendrá a crear el ambiente auténtico para el hombre, y la aceptación del misterio será la savia que mantenga verde la esperanza y lleve el oxígeno al hombre: "aceptar el misterio es consentimiento al ser" 220 .

\footnotetext{
217 Ib., 38.

218 BochensKi, I.M., La Filosofía actual, 201.

219 MOELLER,Ch., Literatura del s. XX y Cristianismo, 254.

220 SCIACCA, M.F., La Filosofía hoy, 398.
} 


\section{b.- Misterio, esperanza y participación}

Para entender lo que significa la palabra misterio es muy conveniente compararla con el significado de problema. Lenz plantea así la cuestión: "no se puede considerar la realidad desde fuera, como en un cuadro, el conocimiento sólo es asequible en el interior de una realidad. Con esta distintición de dentro y fuera, llegamos a una 'distinción central' en la filosofía marceliana: la distinción entre problema y misterio" ${ }^{221}$. La palabra 'conocimiento' que ha empleado Lenz, me parece algo impropia y limitadora; creo que 'experiencia o presencia' -en sentido marceliano- estarían mucho mejor empleadas.

Marcel se explica así: "un problema es algo que encuentro ante mi, algo que aparece íntigramente ante mí, y que por lo mismo puedo asediar y reducir, mientras que el misterio es algo en que yo mismo estoy comprometido, y que por consecuencia, sólo puede pensarse como una esfera donde la distinción de lo que está en mí y ante mí pierde su significado y su valor inicial. Un problema puede resolverse con una técnica apropiada, un misterio transciende toda técnica concebible. Debido a que un misterio es algo reconocido o a reconocer, también puede ser desconocido o activamente negado" 222.

De la relación entre el misterio y la esperanza, se puede decir que la esperanza es el misterio de los misterios, ya que justifica los misterios y da sentido al tú en la obscuridad, en la apertura y el misterio.

"El mistero nos sumerge en el mundo del tú" ${ }^{223}$. Y es el tú el que nos da la esperanza por encima de la muerte, porque abrirse al tú es amarlo y "amar es decir al otro: tú no morirás" ${ }^{224}$. Cuando uno ama, el otro se asienta en la fidelidad, porque le será fiel a pesar de todo, y sabe que él no desaparecerá. Así pues, el misterio, la fidelidad y el amor son el asiento de la esperanza, y en cierto modo la esperanza misma. Y la esperanza es voto, profecía, acto de fe.

"Marcel considera su tesis de la esperanza como la más importante de su obra: con ella se separa radicalmente de Sartre y Heidegger, y a lo que parece de Jaspers" 225 .

Esta frase de Bochenski es elocuente en orden a lo que nos proponemos: intentar demostrar cómo Marcel, a diferencia de todos los otros filósofos de la existencia, lleva a una verdadera esperanza, y que la esperanza es algo típico y sumamente importante en la filsofía marceliana.

221 LENZ, J., El moderno existencialismo, 211

222 MARCEL, G., El Misterio del Ser, 171-172

223 Moeller, Ch., Literatura del s. XX y Cristianismo, 258

224 MARCEL, G., El Misterio del Ser, 293

225 Bochenski, I.M., La filosofía actual, 202. 
Marcel al desembocar en la esperanza se separa de Jaspers, y se dice que para él la transcendencia es algo obscuro, es decir, "no intuible, ni visible ni palpable" 226 .

Jaspers creyó que la transcendencia era un punto de llegada: "Jaspers afirma que los objetos del mundo, incluyendo al hombre, son transcendentes para la transcendencia" 227 .

El punto de llegada no es la transcendencia, es la esperanza, el Ser. La transcendencia es un caminar, aunque a veces, sea un caminar por lo 'metaproblemático', por lo 'misterioso' y por lo 'trágico'.

Jaspers murió viendo la tierra prometida. Según mi parecer, Marcel sí consiguió entrar en la tierra prometida -superar la angustia y la desesperación-, y lo consiguió con su tesis de la esperanza. Por eso no creo que haya que esforzarse mucho en demostrar que esta tesis es considerada por el mismo Marcel como "la más importante de su obra".

El cuidado y el trabajo que el existencialista de la esperanza ha puesto en elaborar, acrisolar, y acuñar este concepto tan lleno, tan profundo y tan central para él, son dignos de mención.

Marcel se pregunta "a qué se refiere la esperanza: ¿a una solución terrena de nuestras dificultades, o por el contrario, a un proceso que se desarrolla en lo invisible y que sólo se iniciaría después de la muerte?" 228.

El mismo autor se responde: "en el primer caso, la esperanza se expondría a sufrir un cruel desmentido; en el segundo desembocaría en lo inverificable" 229 .

Marcel apunta la respuesta: "Me parece, dice, que hay que responder de esta forma: esperar no es esencialmente esperar que..." 230 .

Estas otras frases definen con bastante propiedad lo que es la esperanza: "La esperanza es la exigencia de transcendencia en tanto ésta es el resorte secreto del hombre itinerante" 231; "la esperanza se emparenta con la vida, considerada no en sus manifestaciones, sino en su esencia, que es quizás cierta perennidad" 232; la esperanza es afirmación en el ser; "la esperanza es voto, profecía, acto de fe" ${ }^{233}$; la esperanza es culminación de las relaciones-tú, torre de la catedral de la fidelidad, signo positivo que da sentido a todas las cosas, y de una manera especial a la muerte, a la vida y al misterio.

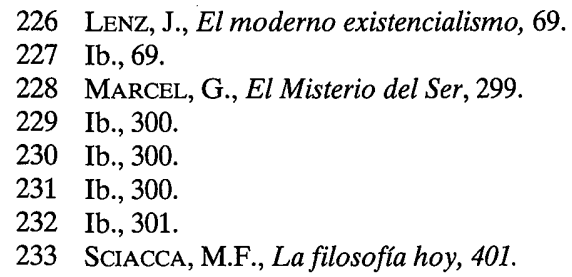


Algo de esto nos indica Bochenski cuando dice: "En el centro de la relaciones-tú se halla una realidad más alta, más libre, en la cual la fidelidad se crea a sí misma en la libertad; pero más fundamental que la fidelidad, es la esperanza. La esperanza posee un peso ontológico: muestra que el triunfo de la muerte en el mundo no es más que aparente y nada último" ${ }^{234}$.

Marcel mismo se pone las mayores objeciones que se podrían poner a su doctrina sobre la esperanza: ¿no será, se pregunta él, una quimera, un simple deseo, o una autosugestión?

A la objeción de que la esperanza sea una quimera o un simple deseo, opone él "la seguridad profética de la esperanza". Pero, ¿sobre qué garantía puede reposar esta 'seguridad'?.

Creo que se podría contestar con una conocida frase de su teatro: "amar a uno es decirle: tú no morirás" ${ }^{235}$.

Esta frase, si se juzga de un modo empirista o positivista parecerá absurda; pues el ser que amo está expuesto a todas las vicisitudes a que está sometidas las cosas y "en la medida en que participa de la naturaleza de las cosas, está sujeto a la destrucción" 236.

Toda la cuestión, muy obscura es verdad, consiste en saber si esta destrucción puede alcanzar a aquello por lo cual este ser es verdaderamente un ser. Ahora bien, esta cualidad misteriosa es la que está presente en mi amor.

Resumiendo la cuestión con palabras un tanto escolásticas, se podría decir: el ser contingente, una vez es, es necesariamente y no puede ser aniquilado por ningún ser contingente; sólo el ser Absoluto puede aniquilar este ser. Ahora bien, el amor para Marcel es algo encarnado en el corazón del ser. Este amor no puede ser destruido por ningún ser contingente. Y si se pasa al plano del ser Absoluto, hay que preguntase con Marcel: "¿es concebible que un Dios que se ofrece a nuestro amor se alce para negar y aniquilar al amor mismo?" 237.

Naturalmente que ese Dios, si se ofrece a nuestro amor, no puede aniquilar el amor, pero, ¿se ofrece ese Dios a nuestro amor?.

Me parece que esa pregunta y la solución que intentaremos dar, son de capital importancia para orientarse en el pensamiento de Marcel.

Se puede responder preguntando: ¿el ser contingente $-\mathrm{y}$ el amor contingente, si pudiera darse- tiene sentido por sí o necesita de otro ser absolutamente necesario, cuya única razón para que el ser contingente dependa de él, es el rebosamiento por amor?

234 BOCHENSKI, I.M., La filosofía actual, 202.

235 MARCEL, G., El Misterio del Ser, 293.

236 Ib., 393.

237 Ib., 396-397. 
El amor del ser contingente, si se 'encerrase' en sí mismo, se corrompería en la angustia, porque el ser contingente no tiene pleno sentido por sí mismo, ni puede resolver todos los interrogantes que puede hacerse. Así pues, el amor ha de ser 'abierto'; es decir, ha de caminar por los 'tús' particulares hacia lo Absoluto, hacia lo infinito, hacia "el momento en que todo quede sumido en el amor" 238.

La seguridad profética podría formularse, con bastante exactitud, como sigue: "Cualesquiera sean los cambios que sobrevengan a lo que tengo ante mis ojos, tú y yo permaneceremos juntos, habiendo sobrevenido ese acontecimiento, que pertenece al orden del accidente, no puede tornar caduca la promesa de eternidad incluida en nuestro amor" 239 . "Or, il faut déclarer avec la plus grande force possible que l'amour humain lui-même n'est rien, qu'il se ment à lui-même, s'il n'est pas chargé de possibilités infinies" ${ }^{240}$

¿Será la esperanza una 'autosugestión'?."La autosugestión consiste, en suma, en crisparse sobre una representación, casi sin concebírsela, como una contracción. La esperanza, por el contrario, tiene caracteres de un aflojamiento, supone un tiempo abierto por oposición al tiempo cerrado del alma contraída" ${ }^{241}$.

La esperanza, pues, permanece en pie a pesar de todo, gracias a su inmortal peso ontológico. La esperanza es también lo eterno de cada uno de nosotros en cuanto es visto por nosotros como eterno, como algo que, pase lo que pase, nunca podrá ser aniquilado.

En realidad, por lo dicho anteriormente, se puede deducir ya que la esperanza culmina la obra de Marcel. Y pienso que esto es uno de los mejores ejemplos de lo que es la esperanza: algo que viene exigido por un contexto de cosas como su culminación, como su explicación, como la confirmación y la eterna ratificación del amor y la fidelidad. Si la esperanza no fuese exigida por todo el sistema, la esperanza sería algo que vendría puesto desde afuera, sería com un estrella que brilla en el cielo, pero que en sí misma no tiene nada de esa tierra desde la que se ve.

La esperanza tiene que ver con la vida; ya va, en cierto modo, encarnada en ésta, como va ya la conclusión encarnada en las premisas, aunque no sea tal explícitamente hasta que no se haga el raciocinio.

La esperanza, aunque va encarnada en la vida, y posee un peso ontológico, no se puede llamar atea. La esperanza es el rostro del Tú que nosotros

238 Ib., 318

239 Ib., 294

240 Ib., 157

241 Ib., 295 
podemos participar, es la mirada con que el Tú mira a los tús en una relación unitiva de amor.

La esperanza es el acorde clave, final e interminable de la sinfonía de los hombres y "de Aquel del que no puede decirse que conduzca la sinfonía, sino que es la sinfonía en su unidad profunda e inteligible, unidad a la que sólo podemos acceder a través de las pruebas individuales, cuyo conjunto, imprevisible para cada uno de nosotros, es sin embargo inseparable de la propia vocación" ${ }^{242}$.

Cuando nos movemos en el terreno del misterio, la dificultad para explorar es mayor, ya que el lenguaje de lo misterioso es distinto del lenguaje y contexto de lo problemático. Es una dificultad comparable con la que se produciría si tuviéramos que formular juicios condenatorios imparciales sobre una persona muy querida. La categoría de juicio está en distinta escala que la categoría de amor, fidelidad creadora, etc. En el segundo caso estamos en el terreno de lo inverificable: "Es evidente que el nexo intersubjetivo de ninguna manera puede comprobarse; sólo puede reconocerse...¿Qué buscamos exactamente? No es un hecho, ni tampoco una forma en el sentido tradicional del término; sin duda más valdría hablar de una estructura, a condición de recordar que cuando se habla de estructura habitualmente se evoca algo que se presenta como un objeto susceptible de considerarse desde fuera. Ahora bien, aquí se trata, si puede decirse así, del interior de la estructura, y de un interior del que debemos reconocer que, en nuestra condición de seres finitos y un tanto ligados al habitat terrestre, no nos es dado hacer corresponder un exterior" ${ }^{243}$.

Para Marcel la verdad está en las cosas y no en el juicio. Intenta descubrir la verdad de las cosas, o mejor, de las personas y de sus relaciones, que las constituyen. Las personas existen más eminentemente que los otros entes porque son los únicos seres capaces de desvelar la verdad del ser y sus relaciones (nos referimos a los seres-que-están-en-el-mundo).

"La intersubjetividad a la que hemos accedido no sin esfuerzo, debe ser en realidad, como el terreno sobre el que vamos a establecernos para continuar nuestras investigaciones ...Pero una toma de posición semejante, de inmediato pone de manifiesto el carácter anticartesiano de la metafísica hacia la cual vamos a tener que orientarnos. No basta decir que es una metafísica del ser: es una metaafísica del somos, por oposición a la metafísica del yo pienso" 244 .

242 Ib., 319

243 MARCEL, G., Le Mystère de l'Etre, 188 y 189

244 Ib., 186-187 
Si bien la intersubjetividad y el ser no se identifican, sí tenemos que afirmar que son frutos del mismo territorio y que están interrelacionados: ¿Puede decirse que, en suma, hemos llegado a identificar ser y subjetividad? ¿Diremos que el ser es la intersubjetividad?

De inmediato diré que no creo posible suscribir esta posición tomada literalmente. La verdad me parece aquí mucho más sutil, y exige enunciarse en un lenguaje a la vez más riguroso y más matizado.

"Lo que creo percibir -y en este dominio sin duda es preferible expresarse en un tono dubitativo- es que el pensamiento que se dirige al ser restaura al mismo tiempo a su alrededor esa presencia intersubjetiva que una filosofía de inspiracion monádica comienza por exorcizar de la manera más arbitraria" 245 .

Entramos en la esfera del tener (avoir) cuando el ego protagoniza gnoseológicamente la verdad, como si la verdad estuviera sólo en el juicio, y todo pudiera ser objetivable y categorizable. El nosotros relacional nos sumerge en el lenguaje más inmediatamente captable, que el espesor del ser adelgaza en la medida en que el ego pretende atribuirse una posición central en la economía del conocimiento. Inversamente, cuanto más reconoce el ego. que es uno entre otros, con una infinidad de otros con los que mantiene relaciones a menudo indescifrables, más tiende a recobrar el sentido de esta espesura.

Seamos cautos, sin embargo: si nos limitamos a decir que el ego es simplemente uno entre otros, lo atomizamos, lo reducimos a la condición de un elemento numerable. Ahora bien,"si insistí tanto en la intersubjetividad, es justamente para poner el acento sobre la presencia de una profundidad sentida, de una comunidad profundamente arraigada en lo ontologico, sin la cual los lazos reales humanos serían ininteligibles o, más exactamente, deberían considerarse exclusivamente míticos" ${ }^{246}$.

Se trata de textos centrales, siempre necesarios, para entender a G. Marcel, y su concepcion dialógica. A pesar de la dificultad que uno encuentra al caminar entre estos textos, hay que reconocerle a Marcel el esfuerzo en clarificar la cuestión mediante 'aproximaciones sucesivas' que nosotros debemos reiterar. "En un lenguaje más concreto, digamos: no me preocupo por el ser, sino en la medida en que tomo conciencia más o menos indistinta de la unidad subyacente que me une a otros seres cuya realidad presiento" 247 .

245 Ib., 191-192.

246 Ib., 192.

247 Ib., 192-193. 
Estamos situados en una región óntica donde la libertad humana adquiere el máximo protagonismo. Estamos más en el reino de la voluntad que en el reino de la crítica. El consentimiento al ser no puede imponerse, por tanto podemos desconocer el ser o negarlo.

No se trata, sin embargo, de un camino irracional, sino del reino de la libertad creadora. "El ser es" resulta una proposición dicha a mi libertad y a otros seres libres. El reino del misterio no es irracional, pero tampoco objetivable, es reconocible o a reconocer. La ontología tiene atmósfera misteriosa.

Marcel habla de sus coincidencias con la ontología de Heidegger, pero marca también la diferencias con este autor admitiendo que pueda ser "existencialiste, ce qui est fort douteux, il a rejeté catégoriquement la dénomination d'athée.

J'ajouterai qu'en fait, lui et moi, nous sommes infiniment plus proches l'un de l'autre qu'il ne l'est de Sartre ou que je ne le suis de Jaspers" ${ }^{248}$.

$\mathrm{Si}$, 'la claridad es la cortesía del filósofo', uno no siempre puede ser todo lo 'cortés' que desearía. Incluso se podría decir que la cortesía la regatearon los dioses a los aprendices de filósofos. Por eso, intentaremos hacer un poco más transparente el pensamiento dialógico y el ser como punto de encuentro y diálogo.

G. Marcel, pone el ejemplo concreto y sencillo del marido que poco a poco llega a descubrir a su mujer como auténtica persona y que trasfigura no solamente su experiencia de la mujer sino también su propia vida y sus propias relaciones humanas, de modo que entonces llegará a poder sacrificar caprichos y diversiones que antes tenían una importancia extraordinaria para él. "Estamos ante un cambio de experiencia que ilustra directamente mi pensamiento. Este cambio afecta al centro; digamos más bien que el pensamiento sustituye un centro por otro; y desde luego la palabra pensamiento no es muy exacta, puesto que se trata de la actitud misma del ser considerada en su totalidad, y en tanto toma cuerpo en sus actos" ${ }^{249}$.

"El pensamiento dialógico es un nuevo estilo de ser y de pensar la relación humana" ${ }^{250}$. Marcel habla con insistencia de su teatro por que en él hay ejemplos vivientes de esta relación dialógica. El teatro es la quintaesencia de su filosofía vertida en situaciones concretas y relativamente transparentes:

248 MARCEL, G., Testament philosophique. Revue de Metaphysique et de Morale 3(1969), 254-255.

249 MARCEL, G., Le Mystère de L'Etre, 50.

250 LOPEZ QUINTAS, A., Conferencia pronunciada en el Congreso de Filosofía de Alcalá de Henares, Julio de 1979. 
"Si ahora, después de estas largas y difíciles explicaciones, me vuelvo hacia la cuestión formulada al principio de esta conferencia, acerca de la relación entre mi persona y mi obra, sin que pueda esperar resolverla completamente, creo que por lo menos puedo decir lo siguiente: si tengo derecho a hablar de una presencia de mí mismo en mi obra, es únicamente en la medida en que este yo ha encontrado progresivamente una unidad entre los distintos aspectos que al principio habían estado disociados. Pero es evidente que esta unidad debe de ser comprendida dinámicamente... Cuanto más se considere esta unidad, más se verá que reside en la unión de una actividad creadora, por una parte, y por otra, de una filosofía de esta actividad creadora. Pero al expresarme así, creo que os ayudo a que comprendáis mejor lo que vengo diciendo desde hace diez años, que en el conjunto de mis obras, el teatro ocupa el primer lugar y no la filosofía" ${ }^{251}$.

Pondremos también un ejemplo tomado de Heidegger. Al leer a $\mathrm{M}$. Heidegger, uno tiene la impresión de que está releyendo a Hegel. Parece que quiere aclarar algo que Hegel no especificó bien. "Pero entonces, ¿es la obra todavía obra cuando está fuera de la relación? ¿no pertenece a la obra, precisamente eso de estar en relaciones?. En todo caso sólo resta preguntar en cuáles relaciones está.

¿Adónde pertenece una obra? La obra, como tal, únicamente pertenece al reino que se abre por medio de ella. Pues el ser obra, (el ser) de la obra existe y sólo en esa apertura ${ }^{252}$.

M. Heidegger parece que completó aspectos de la filosofía marceliana de la creatividad. Es un artesano de la creatividad estética. Junto con Hegel profundiza el acto creativo y el resultado del camino creador. La verdad de la creatividad nutre las páginas que Hegel y Heidegger dedican a la Estética.

G. Marcel elaboró preferentemente una ontología de las relaciones humanas, pero sólo dejó iniciada su reflexión sobre la obra de árte y el cometido de la cosas en relación con los seres-que-están-en-el-mundo. Heidegger comprendió que la verdad no es sólamente una relacion personal verdadera, sino que la verdad está también en las cosas: "Llamamos verdadera no sólo a una proposición, sinó también a una cosa, por ejemplo oro verdadero" 253 .

La ontología marceliana, discurre, en algunos momentos, paralela a la de Heidegger. Algunas opiniones heidegggerianas sobre la creatividad

251 Marcel, G., Auf der Suche nach Wahrheit und Gerechtigkeit, 21-22.

252 Heidegger, M., Der Ursprung des Kunstwerkes. Hölderlin und das Wesen der Dichtung, 70.

253 Ib., 82. 
podrían ser subscritas por Marcel."Ser obra significa establecer un mundo. Pero ¿qué es eso de un mundo?...Mundo es lo siempre inobjetivable y del que dependemos, mientras los caminos del nacimiento y de la muerte, la bendición y la maldición nos retienen absortos en el ser...La piedra no tiene mundo, las plantas y los animales tampoco lo tienen; pero sí pertenencen al impulso oculto de un ambiente en que están sumergidos...En cambio la campesina tiene un mundo porque se mantiene en lo abierto de lo existente" ${ }^{254}$.

Pueden crear solamente los seres capaces de comprender la verdad, y sólo los seres abiertos a la apertura del otro pueden ex-sistir en el mundo: "Lo que se dice 'ser' es abierto en la comprensión del ser que es inherente como comprender al 'ser ahi'"' 255 .

Abordamos, pues, el ejemplo del templo griego. Un templo, nos dice Heidegger, no es sólamente un edificio de piedra unida de acuerdo con unos sistemas de fuerzas que lo mantienen en pie. Es también parte del templo, el cimiento rocoso que lo sostiene y cuyas entrañas resisten el empuje de la piedra que brilla bajo el sol. Un templo es el trabajo reunido de muchos obreros, es para un fin, es relativo a un dios, capacidad de congregar, "unidad de vías y relaciones".

Un templo no es solamente el templo construido, sino también el templo para..., para ser visto, interpretado, inundado por la mirada o el sentimiento de los fieles "que tienen mundo".

El pensamiento dialógico procura reunir, actualizar, todas las relaciones de una obra o persona para que confluyan en un punto o en un momento y sean para el hombre, que en ese momento, como en un electrizamiento total, se reúne en el templo o lo consagra: "El establecimiento es, como tal, la erección en el sentido de la consagración y de la gloria. El establecimiento ya no significa aquí la mera colocación. Consagrar significa en el sentido de que, en la construcción que es obra (Werkhaft), lo sagrado se abre como sagrado y el dios es llamado a lo patente de su presencia" 256.

La presencia es una forma especial de ser en relación con otro. "Mediante el templo está en él presente el dios. Esta presencia del dios es en sí la ampliación y delimitación del recinto como sagrado. Pero el templo y su recinto no se esfuman en lo indeterminado. El templo por primera vez construye y congrega simultáneamente en torno suyo la unidad de aquellas vías y relaciones en las cuales el nacimiento y la muerte, la desdicha y la felicidad, la victoria y la ignominia, la perseverancia y la ruina, toman la forma y el

254 Ib., 74-75.

255 Heidegger, M., Sein und Zeit, 470.

256 HeIDEgGer, M., Der Ursprung ds Kunstwerkes, 73-74. 
curso del destino del ser humano. La poderosa amplitud de estas relaciones patentes es el mundo de este pueblo histórico. Partiendo de tal ámbito de él se vuelve un pueblo sobre sí mismo para cumplir su destino" 257.

Otro pensador alemán, M. Buber, descubrió, paralelamente a Marcel las posibilidades del pensamiento dialógico. También entendió que la relación era, en realidad, polivalente: "Le monde de la relation s'établit dans trois sphères:

La première est celle de la vie avec Nature...

La deuxième est la vie avec les hommes. La relation y est manifeste et explicite. Nous pouvons y donner et y recevoir le Tu.

La troisième est la communion avec les essences spirituelles" ${ }^{258}$.

El libro de M Buber, Ich und Du, adquirió gran difusión y puede contribuir notablemente al conocimiento del pensamiento dialógico. Pero, el lector suele poetizar este libro, perdiendo así las grandes posibilidades filosóficas que tiene. Lo dialógico no es -o por lo menos, no es sólo- poesía y profecía, es fundamentalmente ontología.

A partir de Rosenstork(1924), el pensamiento dialógico encuentra eco en temáticas como el diálogo, el misterio, etc. También en $\mathrm{H}$. U. von Balthasar, A. Brunner, K. Rahner, M.D. Chenu, J. Mouroux, O. Semmelroth, H. de Lubac, J. Daniélou, D. Congar, y otros.

El movimiento dialógico se extiende a la literatura. H. Hesse sería un buen ejemplo. El lobo estepario habla del rico potencial que podrían comunicar algunas personas, aisladas por diversas circunstancias. Se trata de un lamento, de un grito de incomunicación que nos despierta a buscar nuevas formas y más auténticas de comunicarse. Los lobos son buscadores, pueden caminar solos toda una noche, pero necesitan reunirse con otros. H.Hesse -escritor dialógico- cita expresamente a pensadores dialógicos para expresarles su simpatía: “...Una edición completa de Goethe y otra de Jean Paul eran al parecer muy usadas, lo mismo Novalis y también Lessing, Jacobi y Lichtenberg. Algunos tomos de Dostoievski estaban llenos de papeles cuajados de notas" 259 .

Ya hemos hablado de algunos aspectos del ser, pero resta enfrentarse aún al tema del ser, que es el verdadero caballo de batalla de todo filósofo.

Y surge la pregunta fundamental: ¿Qué es el ser?.

Toda la obra marceliana es una respuesta a esta pregunta, pero intenta, sobre todo, contestar a ella en El misterio del ser y en el Diario Metafísico.

257 Ib., 71

258 BUBER, M., Ich and $\mathrm{Du}, 23$

259 Hesse, H., Der Steppenwolf, 16 
En la segunda parte de El misterio del ser, hay una conferencia que lleva por título esta misma pregunta: ‘¿Qué es el ser?'. En ella se nos dice: “Esta vez vamos a tener que interrogarnos por el ser en cuanto ser. Desde ahora será como si tuviéramos que movernos en una dimensión nueva.

Sin embargo, procedemos con cautela: es evidente que esta dimensión deberá conectarse con aquella en que se situaron nuestras investigaciones precedentes" 260 .

"Y, sin embargo, ¿cómo no sentir una impresión de fatiga y descorazonamiento al abordar este santuario de la ontología tradicional que constituye el ser en cuanto ser? ¿Vamos a internarnos en las profundidades de la metafísica aristotélica, o, lo que es aún peor, en las doctrinas escolásticas que las han prolongado? Lo digo sin ambages: esa no es mi intención" ${ }^{261}$.

De todas formas, por difícil que sea la cuestión del ser, es necesario abordarla, "aún a riesgo de parecer demasiado desenvuelto o aventurado, me propongo, dando por conocido lo esencial de esa historia, colocarme directamente frente a la cuestión. ‘¿Qué es el ser?', y cómo es posible conferirle un sentido inteligible para nosotros" 262 .

En Marcel esa expresión 'para nosotros' tiene una relevancia especial. Se inscribe en la línea marceliana de pensamiento, que pugna por transcender el plano del conocimiento en general, para llegar a lo concreto. "Más positivamente digamos que tengo que pensar no solamente para mí, sino para nosotros, es decir para aquellos que pueden encontrarse con este pensamiento que es el mío" 263 .

La intersubjetividad, o relaciones-tú, va a estar en la base de la ontología marceliana: "Se me preguntará si esa intersubjetividad que coloco en la base de la ontología puede dar lugar a alguna proposición simple y distintamente formulable" 264 .

"Una toma de posición semejante, de inmediato (como ya hemos visto) pone de relieve el carácter esencialmente anticartesiano de la metafísica hacia la cual vamos a tener que orientarnos. No basta decir que es una metafísica del ser: es una metafísica del somos por oposición a la metafísica del yo pienso" 265 .

La intersubjetividad, lo mismo que el ser no es objetivable. "Pero por definición es evidente que lo que llamaré el nexo intersubjetivo no puede dárseme, puesto que de alguna manera estoy implicado en él" ${ }^{266}$.

260 Marcel, G., El Misterio del Ser,181

261 Ib., 183 y 184

262 Ib., 184

263 Ib., 184

264 Ib., 187

265 Ib., 186 y 187

266 Ib., 187. 
"Marcel dice que el ser no es objetivable. Y en el Diario Metafísico añade que es inexhaurible: "L'être comme principe d'inexhaustibilité" ${ }^{267}$.

Estas dos afirmaciones son de la mayor importancia; por una parte, nos manifiestan cómo es el ser, por otra, nos indican las diferencias existentes entre el ser y el tener.

Como apéndice a la segunda parte del Diario Metafísico, se publica un artículo titulado: "Esquisse d'une phénoménologie de l'avoir". Avoir puede tener dos significados en español, haber y tener.

Tener es probablemente más expresivo, pero acarrea el problema de ser transitivo, aunque el hecho de tener, como tal, es algo que se queda en mí, que tengo para mí sólo. Participar es el sentido del ser y del sujeto. "Il est significatif que la relation incorporé dans l'avoir se révéle intransitive"..."Avoir assurément cela peut signifier, et cela (serait) significatif même en principe: avoir à soi, garder pour soi" ${ }^{268}$.

Avoir significa también contenido, posesión y poder. Si yo tengo una cosa, puedo manejarla. Este sentido de manipulación es el que va unido al avoir. Y como sólo los objetos se pueden manipular, resulta que el avoir tiene que ver directamente con los objetos.

Avoir también significa haber, haber en el sentido de tener un determinado contenido, pero el hecho de tener un determinado contenido, nada niega del sentido del tener como tener una cosa mía.

$\mathrm{El}$ avoir es lo clasificable, lo problemático. "Il n'y a de progrès que dans le problématique" 269 .

Tanto Heidegger como Marcel plantean el problema del ser, así como sus etimologías.

Respecto de las relaciones doctrinales entre Marcel y Heidegger, Ramiro Flórez escribe: "pongamos el final como comienzo. Así en las posibles opciones metodológicas para describir esta trayectoria sincopada de la recepción de Heidegger por G. Marcel, me ha parecido lo menos engorroso y más clarificador poner como hito esas palabras que sirven de lema, que contextualizaremos en su lugar, y que pueden tomarse como el modo definitivo de habérselas Marcel con Martín Heidegger. El rechazo final del planteamiento heideggeriano obliga a cuestionar la palabra clave de toda la Historia de la Filosofía: la palabra ser" ${ }^{270 .}$

267 MARCEL, G., Journal Métaphysique, 127

268 MARCEL, G., Esquisse d'une phénomenologie d'avoir, 200

269 MARCEL, G., Etre et Avoir,125

270 FlOREZ, R., La recepción de Heidegger por G. Marcel, Estudios Filosóficos, 109(1989)581 
Entiende Ramiro Flórez que Marcel a través de su método característico, discursivo, experiencial y cautelar, meticuloso y reiterativo que se va fragmentando en interrogantes, tanteos, sugerencias, al hilo de las propias posiciones, delimita lo que realmente es más interesante mirado desde una perspectiva de filósofo introspectivo, moralizador y pedagógico. "Esos fragmentos de preocupada atención y análisis se aunarán al final en la cuestión radical y definitiva: no se trata del ser, sino de ser" 271.

Considera Flórez que Marcel tenía algunos prejuicios o condicionantes para leer de manera imparcial a Heidegger. Marcel era un judío convertido al existencialismo, con un claro temparamento antinazi.

Este socrático cristiano se consideraba asesor de una juventud desorientada y de un mundo roto. A partir de análisis profundos de su experiencia personal, pretende sacar consecuencias edificantes para todos. El hecho de que Heidegger, -fuera del catolicismo-, buscase modelos de ética y saber en el mundo griego, desconcierta bastante a Marcel.

Heidegger es un griego, trata de escrutar la mirada nocturna de los buhos sapientes de Grecia, siempre está ahondando en la lengua alemana, y en consecuencia, escribe Marcel, no es aconsejable ni útil para dirigir a la juventud.

Pero volviendo a la cuestión del ser, el tema se plantea "sin preámbulos y casi a quemarropa:

a) ¿Qué es el ser? o

b) ¿Qué es ser?. Debe entrar también a debate "la zona de indeterminación" que existe entre ambas fórmulas. Marcel adelanta su posición, pero sin traer para nada al habla otras doctrinas suyas...Ahora la cuestión la limita así: si preguntamos por el ser puedo subentender que esas palabras recubren el ser por excelencia. Y en el límite, la cuestión del ser se conecta con la de Dios" 272. Por eso, piensa Marcel, que el místico debe tomar la palabra justo allí donde el filósofo debe enmudecer.

El ser es plenitud que no puede decepcionar. La intersubjetividad es "una profundidad sentida, una comunidad profundamente arraigada en lo ontológico, sin la cual los lazos reales humanos serían ininteligibles o exactamente, deberían considerarse exclusivamente míticos" 273 .

El problema de Dios, en realidad es el misterio de Dios, porque la expresión 'problema de Dios' es ‘contradictoria' y sacrílega, concluirá Marcel.

271 Ib., 581

272 Ib., 599.

273 MARCEL, G., El Misterio del Ser, 192. 
"La encrucijada de todas las dificultades, escribe Feliciano Blázquez, radica en la noción de transcendencia, que conlleva siempre una 'desproporción esencial' de Dios con respecto al hombre, tanto en lo referente al ser como al conocer. Es la 'inexhaustibilidad' o, como prefiere decir Marcel, la 'inagotabilidad de Dios' con relación a todas las formas de conciencia y pensamiento. De ahí que al hombre le resulta imposible acercarse, mediante sus propias facultades, al conocimiento de Dios, tal como él es en sî" ${ }^{274}$.

El hombre busca vías no sólo racionales para aproximarse a Dios, al Ser. De las numerosas pruebas para demostrar -a lo largo de la historia- la existencia de Dios, Marcel sólo asume algunas.

Le resulta particularmente sugestiva la 'prueba ontológica'. Esta resiste porque se instala en Dios desde el primer momento. Ello quiere decir que más que una idea es un modo de presencia. El argumento ontológico de San Anselmo más que una prueba, es un intento de comprender, una disposición abierta a comprender. Más que de una analogía del ser, se trata de una 'analogía de la gracia'. El hombre no podría descubrir al Ser perfecto, si éste no se revelase al hombre que lo busca.

"Podríamos decir que la exigencia de Dios no es otra cosa que la exigencia de transcendencia descubriendo su auténtico rostro" ${ }^{275}$.

Si bien el hombre no llegará nunca, -según Marcel-, a saber plenamente cómo es Dios, sí podría conocer qué no es Dios. En el fondo, ser es participar en lo que es eterno. El deseo de participar en lo eterno, se identifica, en parte, con la exigencia de ser y la exigencia de transcendencia.

"Pienso, -afirma Marcel-, que lo más importante de mis proposiciones consiste en afirmar filosóficamente aquende toda especulación teológica, la indisolubilidad de la esperanza, la fe y la caridad" ${ }^{276}$.

Marcel considera que sus reflexiones son filosóficas aunque lleguen a conclusiones que no resultan distantes de aquellas a las que llegaría la teología: su pensamiento "permanece más acá de la revelación propiamente dicha y del dogma, pero al menos es una vía de aproximación, y como caminantes, como peregrinos, en un camino difícil y sembrado de obstáculos, tenemos la esperanza de ver brillar un día esa luz eterna que no ha dejado de alumbrarnos desde que estamos en el mundo, esa luz sin la cual, podemos estar seguros, jamás nos hubiéramos puesto en camino" 277.

274 Blazquez, F., Gabriel Marcel; del existente concreto al tú Absoluto. Tesis doctoral, 4.

275 MARCEL, G., El Misterio del Ser, 183.

276 Ib., 319.

277 Ib., 319. 


\section{CONCLUSIONES. REFLEXION CRITICA}

a.- Metodología de Marcel, un filósofo 'étant en route'.

En su Testamento Filosófico, conferencia pronunciada en 1968 en el congreso Internacional de Filosofía de Viena, Marcel sugiere cuáles son las conclusiones fundamentales que pueden extraerse de su obra.

El marco para su Testamento lo considera Marcel muy apropiado porque Viena es, para él, según hemos recordado, la "ciudad de los encuentros" y la "capital de la música".

Su filosofía quizá pudiera titularse: filosofía para el encuentro, o contribución a una fenomenología del encuentro humano.

En este sentido, la palabra 'búsqueda' es la clave. Búsqueda quiere decir apertura, disponibilidad, andar 'a la búsqueda de la verdad', 'étant en route'.

En estos sentidos, la palabra búsqueda, asegura Marcel, debería anteponerse también a todos sus escritos, a toda su producción.

La música y el teatro están indisolublemente mezcladas con su producción filosófica; constituyen un 'acceso inmediato' a los niveles más profundos de la experiencia, resultan muy adecuados para profundizar en la experiencia.

Se trata, pues, de una filosofía concreta, que puede ser encarnada en personajes de teatro, en personas reales, en situaciones cotidianas.

Marcel es, pues, un filósofo al que le gusta partir de lo concreto, porque la abstracción facilita la obnubilación de la verdad.

Su pensamiento resulta deliberadamente asistemático, quizás para oponerse con más contundencia a los sistemas idealistas, que en su juventud hicieron el papel de cantos de sirena, que Marcel más tarde rechazó.

Como filósofo libre y asistemático, Marcel no quiere ser incluido en ningún 'ismo', en ninguna escuela. En su Testamento Filosófico recalca que no le gusta el término 'existencialismo' para clasificar o encuadrar el pensamiento creado por él. Si utilizó alguna vez, este término fue con la firme intención de recusarlo.

Fue una etiqueta que le pusieron y que él rechaza. El hecho de que al lado de 'existencialismo' coloquen el adjetivo 'cristiano' no mejora la clasificación, porque continua sin gustarle.

Marcel prefiere que le llamen 'filósofo itinerante' porque nunca dejó de considerarse como 'étant en route'.

En el prefacio a El Misterio del Ser, Marcel confiesa que si debe resignarse a buscar un rótulo, aceptaría el de neosocrático cristiano, o 'neosocratismo cristiano'.

En el Congreso de Roma de 1946, Marcel descubrió que se le tildaba de 'existencialista', adjetivo que no lo gustaba nada. 
Posteriormente se le preguntó si un volumen dedicado a Marcel por la Editorial Plon podría llevar el título genérico "Existencialismo cristiano". Marcel consultó a un hombre de confianza, Louis Lavelle. Este le contestó que esas dos palabras no le gustaban por eso comprendía que no le gustasen al autor de El Misterio del Ser, pero en fin, resolvió, que podrían aceptarse como una concesión al editor.

No obstante, estos dos términos (existencialismo cristiano) sufrieron tantas variaciones y deformaciones que Marcel, se arrepintió profundamente de haber hecho esa concesión, tal como hemos visto más arriba.

Al parecer fue Sartre quien 'imprudentemente' colaboró a la difusión de la terminología 'existencialismo cristiano' para oponerla a 'existencialismo ateo', dentro del cual se consideraba él.

Por su parte, Marcel ya le dejó bien claro que esta clasificación resultaba improcedente.

A la muerte de Marcel, el profesor López Quintás publicó un artículo en ABC, titulado "Gabriel Marcel y su testamento filosófico", en el que rechaza los términos existencialismo o existencialista para catalogar el pensamiento del autor que nos ocupa; prefiere utilizar el término 'existencial', por las razones siguientes: Un pensador existencial aceptará que la persona tiene 'un modo preciso de ser', pero añadirá infaliblemente que 'su existencia no le viene dada del todo' y por eso mismo 'debe hacerla en contacto mútuamente fecundante con el entorno'.

Para clarificar cuestiones relativas al método de Marcel, la profesora Parain Vial, con la que mantuve correspondencia al efecto, me recomienda leer: Entretiens Paul Ricoeur - Gabriel Marcel. Estas entrevistas constituyen una exploración profunda de la obra marceliana a fin de clarificar lo clarificable, reconociendo los caminos (método) que permitieron llegar a unos resultados, o transcender unos niveles de experiencia para ir hacia otros niveles mucho más auténticos, pilares del encuentro, del misterio, del ser.

Ricoeur considera que la obra de Marcel podría rotularse como una exploración o una lucha contra los sistemas, o contra 'el espíritu de sistema'.

Bochenski reconoce que se trata de una filosofía asistemática, y que, precisamente por ello, la comprensión de ese pensamiento no resulta demasiado fácil. Piensa incluso que hasta la fecha nadie lo ha expuesto de un modo adecuado y sistemático o sistematizado.

El método de Marcel está emparentado con el 'Método Jericó', descrito por Ortega. Consiste este método en aproximaciones sucesivas hacia un objetivo alrededor del cual damos vueltas para profundizar en su significado, en sus niveles de experiencia o de presencia.

Ya en 1914 Marcel descubría la insuficiencia de la inmanencia, un postulado que conviene dejar atrás. La transcendencia es el camino que nos per- 
mite salir de la trampa. Para Marcel la transcendencia es una tabla de salvación, pero, al propio tiempo, constituye una realidad bien palpable, a la que estamos abiertos, y a la que aceptamos como un 'consentimiento al ser'.

\section{b.- Novedades de la filosofía de Marcel}

Feliciano Blázquez, al hacer una 'valoración crítica y creadora de la obra de Marcel', considera que se trata de una obra 'amplia, dispersa y asistemática'. Entiende que para juzgar rectamente esta obra hay que desembarazarse de prejucios, dogmatismos y apriorismos. Al parecer, los violentos ataques que ha recibido la obra de Marcel proceden de personas que no han sabido sacudir sus prejucios.

"Creemos honestamente, -continúa-, que el esfuerzo marceliano por distinguir entre experiencia y elaboración conceptual de la experiencia, por encontrar una adecuada relación entre intuición y concepto, como si de un viaje de ida y vuelta se tratase, -de la experiencia al concepto y del concepto a la experiencia-, ha abierto cauces para una redefinición más amplia, y sintética de la filosofía" ${ }^{278}$.

El esfuerzo de Marcel por hacer un lenguaje o una terminología más fluidos, fue interpretado por algunos como una manera de hacer poesía, o simples expresiones emotivas. Quienes estudian a Marcel sin prejuicos, reconocen su creatividad así como la originalidad de su pensamiento, uno de los más valiosos de nuestro siglo.

La estructura humana es dialogal. Su pensamiento podría calificarse de dialógico en cuanto que el encuentro y el diálogo conforman la características más significativas de la persona.

Este ser itinerante, que somos nosotros, se va haciendo a base de intimidad y apertura, de libertad y enraizamiento en los otros, que poseen el secreto de lo que somos.

Así se crea también un nuevo lenguaje sobre Dios. Considera Marcel que el lenguaje religioso e incluso el metafísico, son lenguajes típicos de las personas.

"En el encuentro puede tener lugar la experiencia religiosa, y cívicamente, a través de las categorías de encuentro, puede ponerse el tema de Dios" 279.

Dios es un interlocutor que interviene en nuestro diálogo, es dialógico, en relación con nosotros. Sin él, jamás nos hubiéramos puesto en camino.

278 BlazQuez Carmona, F., Gabriel Marcel: Del Existente concreto al Tú Absoluto. Tesis doctoral, 526 .

279 Ib., 531. 
"El lenguaje sobre Dios será siempre transgresivo a los datos inmediatos de la experiencia. Conduce a una realidad que no es accesible sino merced a una interpretación" ${ }^{280}$.

$\mathrm{Ni}$ la técnica, ni el lenguaje positivista, son camino adecuado para el encuentro con el Tú absoluto. Ambos confían demasiado en sus posibilidades. La prepotencia les inclina a negar la metafísica, la capacidad de transcendencia.

El hecho de que sólo resulte válida la experiencia que se traduce en términos empíricos, encierra a la técnica y al positivismo en un callejón sin salida. Ni la ténica, ni el positivismo satisfacen las aspiraciones profundas del hombre.

"Hay otros niveles de verdad y de sentido, que suscitan formas de comunicación interpersonal que complica a las personas y se dirige a esa dimensión de profundidad que hay en el hombre. Es decir, el lenguaje metafísico, el lenguaje religioso en general y el lenguaje sobre Dios, en particular, pueden ser lenguajes significativos" ${ }^{281}$.

El Dios creador, el Dios del Antiguo Testamento no se podía identificar con el Nous griego, fuerza cosmológica organizadora o teleológica. Tampoco coincide demasiado con algunos tipos de Escolástica, que centran su argumentación en un retorno constante a la causa primera: "La libertad del Dios bíblico resulta inaccesible al procedimiento regresivo. Era indispensable una donación, -presupuesto de toda comunicación del hombre con Dios- ...por eso, la primera tentativa marceliana debía consistir en renovar el lenguaje. ...Intentó desmontar la categorías griegas, para encontrar otras más flexibles y humanas, que abrieran la posibilidad de una concepción genuinamente existencial de Dios" ${ }^{282}$.

Zubiri ya había reconocido que Dios más que una causa es una persona. Marcel convierte esta afirmación en el punto central de su tesis sobre Dios. Las puertas de acceso a la realidad divina no pueden ser causalistas, sino algo característico de las personas: Interpelación, presencia, amor, relaciones-tú, fidelidad.

El amor es participación, y amamos participando, dirá Marcel. Desde el tú particular, personal, Ilegamos al Tú Absoluto: "Si yo participo de ese amor, ya no intentaré hacerlo entrar en mis casilleros lógicos: todo lo contrario, yo mismo todo entero me refundiré para penetrar en él" ${ }^{283}$.

280 Ib., 532.

281 Ib., 532.

282 Ib., 533.

283 MARCEL, G., Journal Métaphysique, 229. 
c.- Balance y homenaje

En el centenario del nacimiento de Marcel, la revista "Estudios Filosóficos" hace un balance de la filosofía de Marcel, que al final, se convierte en un homenaje.

Feliciano Blázquez escribe así: "La revista "Estudios Filosóficos", de los PP. Dominicos de Valladolid, ha tenido la feliz iniciativa de dedicar este número monográfico a una de las voces más originalmente frescas de este siglo, aun cuando los cenáculos 'oficiales' o 'de vanguardia', según ellos, de la filosofía española, se empeñen en olvidarla, acallarla o minusvalorarla. Gabriel Marcel ha sido un pensador libre y, quizá, por ello, incomprendido por muchos. Ha denunciado todo mesianismo, unívoco o reductor, de la razón pensante y aquellos esquemas de experiencia que establecen una relación de dominio sobre la realidad, para elaborar un concepto más amplio de experiencia. Existe, -proclama-, una experiencia de sentido, que se sirve de un lenguaje no objetivista, unívoco, exacto, sino abierto al contacto personal, a unas realidades más profundas y significativas. En otros términos, conocer no es dominar, producir, poder, sino hacerse, desarrollar unos valores que permitan al hombre ser persona.

Gabriel Marcel, educado en las raíces del humanismo-personalista de la 'transcendencia', se ha empeñado en transmitir que la verdad no posee un estatuto abstracto ni teórico, sino que es un acontecimiento. Hay una responsabildiad personal de la verdad, en la que el hombre no puede ser reemplazado por nadie. De ahí que el mensaje de su filosofía no pueda ser otro que el de la invitación constante a la libertad creadora. Ahí, precisamente, se sitúa su crítica frontal a la cosificación, a un mundo objetivado, problematizado, en el que el hombre acaba por tenerlo todo y no ser nadie. Por eso, los ídolos del hombre actual, -la producción, la técnica, la manipulación, la ambición obsesionada, el comsumo...- cuanto más ricos son, más pobre es el hombre. "Creemos honestamente que el esfuerzo marceliano por distinguir entre experiencia y elaboración intelectual de la experiencia, por encontrar una adecuada relación entre la intuición y el concepto, por delimitar las fronteras entre lo problemático y los misterioso, ha abierto cauces para una redefinición más amplia, y sintética, de la filosofía" ${ }^{284}$.

Estoy de acuerdo en que Marcel es un pensador original y en que su pensamiento tiene un especial frescor, al abordar temas viejos con libertad e independencia. Marcel pone la razón en su sitio, sin permitir que se convier-

284 Blazquez Carmona, F., Aproximación crítica a la bibliografía hispánica de Gabriel Marcel, Estudios Filosóficos, 109(1989) 603-604. 
ta en la loca de la casa. Proclama la validez de la 'experiencia de sentido', la profundización en los distintos niveles de la experiencia.

El conocimiento no es ni una forma de dominio, ni una manera de producción; conocer es fundamentalmente participar en el acto creador de valores que nos facilitan ser personas honestas, humanas.

Marcel no adora los falsos ídolos del consumo, la producción o la técnica. Dichos instrumentos favorecen más fácilmente la ambición que la comunicación.

La corriente de la ambición desemboca en el mundo problemático, el mundo roto.

Por el contrario, la atmósfera del misterio, de lo creativo y auténtico, es la que posibilita la respiración y el crecimiento de los seres humanos. Esta permite abrir 'cauces para una redefinición más amplia, y sintética, de la filosofía.

Marcel considera que la filosofía de Nietzsche es un fruto de la filosofía de la modernidad; reconoce que, en algunos aspectos, Nietzsche refleja bien la situacion actual. Su pensamiento describe adecuadamente la imagen rota del hombre, del mundo.

El autor de Así habló Zaratustra describe bien el campo de combate, la angustia existencial, la transmutación de todos los valores.

No obstante, Nietzsche se queda atrapado en las trincheras, no logra transcenderlas. Excluye la transcendencia que es la puerta de salida.

Marcel critica este gran error de la filosofía de Nietzsche. Tratará de darle oxígeno, de ofrecer una aportación ontológica. Frente á un mundo destrozado, Marcel encuentra esperanza. Descubre que, en el fondo, Nietzsche querría superar el nihilismo; pretendía hacer de despertador de la conciencia de Occidente.

Cuando el hombre niega la transcendencia, y se niega a la transcendencia, incurre en los peores errores; cuando admite las relaciones-tú y la transcendencia, entonces encamina sus pasos hacia el verdadero camino: llegar a ser lo que, de alguna manera, ya eres.

José Seco Pérez observa la obra de Marcel a trävés del cristal del pensamiento de Nietzsche: "Marcel aprecia en la filosofía nietzscheana un momento decisivo en el pensamiento contemporáneo, el núcleo de convergencia de toda la tradición filosófica de la Modernidad. Lo que realmente está en juego es una interpretación del mundo que excluye toda transcendencia, que excluye lo último y decisivo. Marcel tratará de proporcionar a la crítica nietzscheana la aportación ontológica suficiente que se trasluce en los distintos núcleos de profundidad y que se deducen de una lectura existencial de su obra.

Marcel, al reflexionar sobre la obra de Nietzsche, se esfuerza en comprender el tiempo de hoy, así como su propio horizonte espiritual. Su filosofía 
le ofrece la imagen rota del hombre. El hombre moderno ha sido privado de la imagen tranquilizadora que tenía de sí mismo desde hace siglos. De esta forma, por medio del análisis profundo que hace de la obra y pensamiento nietzscheanos, Marcel se integra en lo más profundo del debate contemporáneo, toda vez que Nietzsche deviene el cruce de caminos obligado de todos aquellos que quieren comprender los profundos cambios, tanto espirituales como culturales que acaecen desde hace tiempo en nuestro presente.

Para Marcel la aportación nietzscheana esencial consiste fundamentalmente en hallar el lugar existencial desde donde se juega el destino del hombre, desde donde se opera su campo semántico. Marcel, pues, se centrará en esta situación del hombre que rompe con lo transcendente. Este discurso antropológico viene a significar el recurso a Dios, pues éste se revela en la existencia interior del hombre mismo. La reflexión marceliana se inicia a partir de la contingencia del hombre moderno, un hombre que ha perdido toda referencia divina y que al tener ya asegurada la legitimidad de su existencia, ninguna certeza le conforta. Esta 'veritable nécrose' es para Marcel el principio de la angustia metafísica moderna.

La muerte de Dios, según Marcel, precipita la crisis de identidad del hombre; su análisis le conducirá hacia una nueva dimensión del acto filosófico, pues representa el índice existencial de la transmutación de valores y del sistema ontológico del hombre.Tanto Marcel como Heidegger comprueban en la proclamación nietzscheana la expresión del nihilismo occidental y la firme voluntad de superar este "effondre-ment" ${ }^{285}$.

A su vez la fidelidad es uno de los grandes hilos conductores del pensamiento de Marcel. La fidelidad se instala en el mundo misterioso del ser. Casi se puede decir que 'la fidelidad es un modo de ser'. Sólo la fidelidad de los seres garantiza la estabilidad de los seres, garantiza la fortaleza de nuestra fidelidad; aunque el verdadero Ser avala cada momento de fidelidad humana; claro que este aval no siempre, o casi nunca, resulta patente.

No obstante, Marcel pretende mostrar el valor de la fidelidad con argumentos que están más acá de la revelación. En medio de las dificultades diarias, y de los problemas de nuestro siglo, la fidelidad demuestra "la fecundidad del ser", en el que participa y por el que es lo que es: algo permanente que puede vencer a la muerte misma.

El amor y la esperanza constituyen otros dos pilares que garantizan la indestructibilidad de la fidelidad creadora.

285 Seco Perez, J., "Nietzsche y Marcel. Testigos de la Modernidad, Estudios Filosóficos, 109 (1989) 576-577 
Fernando Vela investiga la raíz ontológica y las vertientes existenciales de la fidelidad en el pensamiento de Marcel: Como venimos viendo, la fidelidad tal como la concibe Marcel, es un modo de ser -más que un comportamiento puntual- complejo, multidimensional y que exige una permanente tensión si no quiere devaluarse en cobertura de abandonos y repliegues. El mundo en que somos fieles o en el que, por el contrario traicionamos la verdad del ser, de la existencia, es un mundo ambiguo, ofrece múltiples posibilidaddes para desesperar y múltiples reclamos de compromiso creativo. La fidelidad puede, del mismo modo, profundizarse o degradarse en sus formas más burdas, más conservadoras, menos creativas. Lamentablemente, puesto que anida en nosotros la fragilidad, la decepción nos amenaza, la traición es siempre posible.

Hasta tal punto la fidelidad resulta compleja que vista desde fuera, desde una perspectiva abstracta -esto es, que hace abstracción de la implicación existencial del compromiso- se hace difícilmente pensable, incomprensible e impracticable. La dificultad se exacerba cuando el mundo de los hombres, como ocurre en el mundo moderno a juicio de Marcel, se hace una incitación a la negación, a la defección absoluta por ser, al mismo tiempo, un mundo lleno de problemas y animado por la voluntad de no hacer lugar al misterio. Esa constatación no es un pesimismo fatalista. Marcel hace una lectura esperanzada de los males de nuestro siglo, convencido como está de que en el seno de esta existencia y en su favor (actúan) ciertos poderes secretos que la vida no está (a veces) en condiciones de pensar, ni reconocer. No sería abusivo, creemos, citar entre esos poderes regeneradores a la fidelidad creativa.

"Sometida día a día a la prueba, y a esa prueba extrema de la diversas situaciones límites de la decepción -y la decepción de uno mismo-, la desesperación, la noche del sentido, el dolor y la muerte, la fidelidad es prueba a su vez de la fecundidad del ser" ${ }^{286}$.

Marcel considera que la filosofía debe ir mas allá que la técnica. La sabiduría, la filosofía son metatécnica.

Propio del filósofo es asombrarse, ser humilde, -porque conoce bien las limitaciones propias-, estar abierto, dispuesto. Marcel rechaza el orgullo (hybris), la prepotencia.

El hombre que no conoce más mundo que el mundo de la técnica está condenado a "poder sólo lo que puede la técnica". La seguridad dimanada

286 VELA, F., "Raíz ontológica y vertientes existenciales de la fidelidad en Gabriel Marcel, Estudios Filosóficos, 109 (1989) 560. 
de la técnica se convierte, a veces, en la única seguridad. En medio de la obcecación alguien puede pensar que la técnica es la única salvación e incluso el salvador.

La técnica nada puede frente al misterio de la muerte. Su falso poder salvador se transforma en impotencia y desesperación frente a la muerte.

Ante esta desesperación, al hombre le queda, según Marcel, una única posibilidad: recuperar una experiencia profunda de las relaciones humanas, de la fidelidad, del amor, de las llamadas del ser, en el que, -por otra parte-, participa. La exigencia ontológica manifiesta una dimensión del ser absoluto, que es el que da, al final, sentido a nuestra vida.

García Abril investiga la significación de la técnica, y la postura de Marcel ante la misma: "Desde los primeros escritos Marcel declara la guerra al orgullo, la hybris de los griegos, y, en el último, todavía mantiene que es la disposición interior contra la que el filósofo debe estar constantemente en guardia. En el mundo de la técnica el hombre puede lo que puede la técnica. Pero la confianza y la seguridad que da ese poder en un ámbito determinado, al extenderla a todos los ámbitos de la actividad humana, le hace contraerse, replegarse sobre sí y le incapacita para confiar en una realidad extraña, y engendra la pretensión ilusoria de no depender más que de sí, de poder hacerse a sí mismo, la tentación de creer en su valor redentor.

Es, dice Marcel, como una apologética al revés porque pretende mostrar que todo se hace en la realidad sin la intervención de ningún poder creador. Por eso, el descubrimiento de su ineficacia frente a la muerte, conduce a la desesperación y provoca la tentación de suicidio.

La sabiduría que Marcel propone como mediación entre la tecnocracia y la mística, entre la absolutización y la negación, que nos libere del cerco de la desesperación a que nos vemos abocados es, como ya ha quedado indicado, reflexión que nos haga conscientes del desorden y confusión en el medio técnico, que ignora, y pisotea por ello, lo más profundo del hombre y le devuelva el dominio de esa situación, reflexión existencial que nos da conciencia renovada de lo que el hombre verdaderamente es y puede ser, de lo que se oculta bajo la existencia, recuperación de ese fondo olvidado, de esas potencias secretas que son irradiaciones del ser, de un ser en el que participo, que es fundamento y plenitud; el reconocimiento de un absoluto que aflora bajo la forma de exigencia ontológica y que da sentido a nuestra vida. El sentido sagrado del ser" 287 .

287 GARCIA ABRIL, G., "Gabriel Marcel. Significación humana de la técnica", Estudios Filosóficos, 109 (1989) 537. 
Repetidamente Marcel ha escrito que su pensamiento filosófico se manifiesta de una manera preferente en el teatro o en la obra de arte.

$\mathrm{El}$ arte, no es sólamente un resultado, también es, de manera especial, el proceso de creación o elaboración.

Dentro de las modalidades artísticas, parece que la música ofrece más posibilidades. Esta abre una vía de 'acceso inmediato' a los distintos niveles de la experiencia. La creación musical puede desvelar determinados aspectos filosóficos. La experiencia musical, dirá López Quintás se convierte en inigualable fuente de luz. A la luz de la música, -en su creación-, en la ejecución, en la audición, el hombre puede participar en realidades que, aún dándose en el tiempo, están por encima del tiempo.

La música constituye una especial comunicación. Descubre dimensiones ocultas del hombre, devuelve al hombre a sí mismo, y le revela la dosis de eternidad que lleva dentro.

López Quintás recorre una vía muy querida para Marcel, la vía de la Estética, la metáfora de la música: Esta capacidad del arte, sobre todo de la música, para abrir una vía de acceso inmediato a las realidades y fenómenos complejos explica que Marcel haya afirmado con toda decisión que el análisis de ciertas obras musicales maestras pueden dar lugar a toda una renovación de la filosofía y que las Cantatas y Pasiones de Juan Sebastián Bach han contribuido más a la realización de sus conversiones -la filosófica y la religiosa- que los escritos de los más eximios pensadores. Un espíritu congenial, Ferdinand Ebner, solía advertir que 'lo espiritual quiere ser conocido de modo inmediato'.

A qué tipo de inmediatez se refiere y cómo ha de alcanzarse queda espléndidamente de manifiesto al entrar en relación de presencia con obras musicales de gran calidad.

El gran compositor, director y violonchelista español Pablo Casals declaró poco antes de morir que el mundo todavía no ha penetrado suficientemente en lo que significa el hecho de que exista la música. Gabriel Marcel ha contribuido no poco a colmar esta laguna ${ }^{288}$.

Cándido Aniz descubre con bastante precisión lo que Marcel entiende por filosofía. Profundizar en la condición humana, en la condición de seres encarnados, -personas-, que piensan libremente.

La filosofía compromete al hombre porque ésta se hace en 'perspectiva de misterio'.

288 LOPEz Quintas, A., "La experiencia estética musical y el pensamiento filosófico de G. Marcel”, Estudios Filosóficos, 109 (1989) 515-516. 
Pensar y vivir realmente sólo se producen en el ámbito del misterio. El tener conecta directamente con la técnica inhumana.

Las relaciones-tú, el Tú Absoluto, son 'el misterio y la fuente del misterio'.

Como ocurre con todas las filosofías, la de Marcel convencerá a unos, mientras a otros los dejará indiferentes. Estos últimos pontificarán las deficiencias y limitaciones del pensamiento marceliano. Para mí es uno de los más fértiles de nuestro atormentado siglo.

Cándido Aniz prefiere detenerse en la génesis del 'socratismo cristiano', uno de los pocos calificativos que Marcel asumía: "La filosofía/metafísica de Marcel, en su momento germinal, compromete al hombre con el ser, y ha de entenderse como 'reflexión continua en perspectiva del misterio' o realidad metaempírica/metaproblemática. Hacer filosofía es ahondar en la condición encarnada de los seres pensantes/libres que participan en la realidad total; es denunciar las pretendidas suficiencias del 'tener': tener ideas, ciencia, técnica, manipulación/dominio del hombre y de naturaleza, es vivir y pensar en actitud abierta al ser: presencia cautivadora, luminosa, en la que el yo experimenta, se sumerge y toma posesión de sí mismo; es conocer por discernimiento, aproximaciones, revelaciones/intuiciones, situándose en la actitud de 'recogimiento' que, previa 'invocación', enseña a apreciar y vivir en 'fidelidad creadora', a tomar decisiones en libertad y disponibildiad, por referencia al tú humano y al tú absoluto cuya existencia y vida sobrepasan todos los planos nocionales, pues son el misterio y fuente de misterio. Perder el sentido del 'misterio-subjetividad-participación-coexistencia...' es volver a niveles de 'problemas' que distancian pensamiento y vida, pensar y ser, sujeto y objeto, olvidando la necesidad o exigencia ontológica realista. Que estos planteamientos, escasamente metafísicos para el racionalismo, sean o no convincentes en su dramatismo existencial, es otro asunto" ${ }^{289}$.

\section{d.- La participación, clave de la filosofía de Marcel}

En la correspondencia que mantuve con Paul Ricoeur sobre cuestiones importantes en la filosofía de Marcel, Ricoeur me asegura que "la cuestión de la participación en Gabriel Marcel es ciertamente un excelente acceso a su pensamiento" 290 .

El verbo participar puede ser transitivo o intransitivo. En este sentido intransitivo, participar quiere decir tomar parte en algo: una manifestación,

289 AnIz IrIARte, C., "Génesis del socratismo cristiano de Gabriel Marcel”, Estudios Filosóficos, 109 (1989) 480-481.

290 Véase fotocopia de la carta de Paul Ricoeur al final 
una decisión, una boda. En sentido transitivo, participar quiere decir dar o comunicar algo a alguien: Dios participa su bondad, te participo que mañana habrá un homenaje.

Platón ya utilizó el término méthesis, -participación-, sustituyendo al término pitagórico mímesis -imitación-. La participación pues, va más allá que la mera imitación. No obstante, el concepto platónico de participación dista bastante de la experiencia marceliana de la participación.

Aristóteles, tras reconocer que Platón sigue doctrinas de los pitagóricos, excepto en la participación, lleva el tema a su molino que es el de la analogía.

San Agustín, sin olvidar la herencia de Platón, avanza hasta el Dios-creador que deja su luz y su huella en el hombre, en los más íntimo del hombre.

Compartimos la opinión de que el pensamiento de San Agustín está fundamentado en el principio, presente y actuante, de la participación.

Sto. Tomás define la participación como 'partem capere' o 'partem habere'. En este sentido la participación indica un compromiso, una responsabilidad solidaria. Dios-creador y Causa primera deja su huella en los efectos producidos, en los hombres que se parecen a su creador, porque participan, en un cierto grado de $\mathrm{El}$.

K. T. Gallagher en su obra, La filosofía de Gabriel Marcel, que cuenta con un prólogo de Marcel, resume así la cuestión:

-Tema al que Marcel da más importancia: La doctrina de la participación.

-Principal cuestión a abordar: cómo pensar la participación.

-Solución a la que llega: la participación se piensa mediante la reflexión secundaria, que, por su naturaleza, es creadora y libre.

Parain-Vial en su diálogo con Gabriel Marcel ${ }^{291}$, que me dedica con simpatía, explica las posibilidades de la reflexión segunda. Además, sus explicaciones cuentan con la bendición de su maestro y amigo Gabriel Marcel.

Señala Marcel que Parain-Vial es "la intérprete más fiel de su pensamiento".

En la participación hay varios niveles, tal como intentamos demostrar a lo largo de esa tesis. Parain-Vial, que asume la existencia de estos distintos niveles, realiza las reflexiones siguientes -que nosotros compartimos en buena medida-:

291 Dialogue entre Gabriel Marcel et Mme. Parain-Vial, Revue de Métaphysique de de Morale 3 (1974) 383 y ss. (El autor de esta tesis doctoral, dispone de varias cartas de ParainVial, pues ha mantenido una correspondencia, con ella, para la elaboración de esta tesis). 
Para Marcel, el ser es esencialmente 'ser abierto a'. El sentir, la sensación, la encarnación, nos abren al ser, nos permiten participar en el ser. Las relaciones humanas, la comunión no son objetivables. El amor no es 'comprensible' en términos puramente lógicos. El amor, la fidelidad, la esperanza significan apertura a los otros y por ellos "nous sommes plus ouverts activement à la Grâce". Transcender le temps, "c'est participer de façon de plus en plus effective à l'intention créatrice que anime l'ensemble". "La création serait donc une improvisation absolue à laquelle nous participerions" 292 .

La destrucción de la naturaleza por la contaminación de la industria, y del hombre por medio de la guerra, serían los pecados por excelencia, porque cortan de raíz todas las posibilidades de la creación.

La contaminación y la destrucción se parecen mucho al nazismo, cortan cualquier posibilidad de participación. Pero hay que tener presente que el mejor remedio para que no renazca el nazismo, -o los sistemas autoritarios-, es, precisamente, la participación.

"El filósofo debe ser un vigía", para participar en la defensa de la paz, de la naturaleza y de los valores humanos.

El rotativo, "La Vanguardia", en su edición del 10-X-1973, resume así las aportaciones de Marcel 'al universo filosófico': "Marcel le recuerda al hombre su condición de corporalidad y personalidad que no pueden reducirse a un sistema"... "Ante las filosofías del absurdo, la mostración de una posible esperanza... que nos permite seguir luchando no de modo prometeico ni estoico, sino fundamentados en las experiencias de comunión humana"... "Ante las filosofías analíticas, recordándoles que también en éstas...late la cuestión fundamental que no puede ser olvidada del hombre y su destino".

Con motivo de la muerte de Marcel, ABC publica un reportaje de José Julio Perlado; que hace referencia a una entrevista mantenida con Marcel en 1969. En élla Marcel manifiesta que "en España se ha conservado aún lo que llamo 'el amor a la vida'. Creo que en la hora actual, con la elevación del nivel de vida y con su industrialización, aparecen ciertos peligros que antes no existían".

Añade que "la música para mí es algo fundamenal. En ella soy un ecléctico; hay muchos músicos que rechazo. $\mathrm{Y}$, sin embargo, me atraen muchos compositores españoles: esencialmente Falla".

Marcel visitó España, por primera vez en 1933; posteriormente "y en distintas ocasiones, España fue escenario de intervenciones suyas".

292 Parain-Vial, J., Dialogue entre G.Marcel et Mm. Parain-Vial, 384. 
Marcel pone un ejemplo de lo que él llama 'el amor a la vida': "Un día que pasé yo por Barcelona, saliendo de la Catedral un domingo por la tarde, quedé impresionado al ver bailar a gentes la 'sardana' en la plaza frente a la Catedral. Esto para mí es todo un símbolo. Puesto que la 'sardana', como muchos otros bailes, es una danza civilizada, que se enlaza con una especie de alegría y de armonía".

También se refirió a los peligros concretos que acechan a la juventud española: "Uno de estos últimos años, yendo en automóvil de León a Valladolid acompañado por el Vicerrector de la Universidad de León, fuimos conversando sobre España. Yo le pregunté: "El problema de la delincuencia juvenil que nos inquieta actualmente, ¿comienza en España?”. El me respondió que existían casos individuales, pero que no había un problema sociológico. Pocos años después, cuando he vuelto a preguntar sobre esta tema en Madrid, se me ha dicho cómo, poco a poco, la delincuencia juvenil se iba extendiendo".

Feliciano Blázquez publicó en YA un artículo (18.X.73) en el que resalta los hallazgos filosóficos de Marcel: "Arranca del hombre como ser encarnado y en situación para desembocar en el hombre...ser-en-comunión, abierto a la transcendencia -al tú absoluto-mediante la fidelidad, la esperanza y el amor".

Escribe Blázquez que "el público español iba conociendo últimamente algunas de sus ideas en pro de la paz, en defensa de los valores del hombre y en contra de esa permanente tentación deshumanizadora de la civilización actual, debido, sobre todo, a sus colaboraciones en la prensa madrileña y a las recientes traducciones de algunos de sus libros". Escribió "más de setecientos títulos, entre libros y artículos" traducidos a casi todos los idiomas del mundo, incluido el japonés -en donde Marcel entró de la mano de Parain-Vial-.

El 10 de Octubre de 1973, "Le Monde" publicaba lo siguiente (traducción mía): "El filósofo Gabriel Marcel, miembro del Instituto, murió el Lunes, en su domicilio de la calle Tournon, a consecuencia de una crisis cardiaca. Tenía 84 años. Sus funerales se celebrarán en la Iglesia de San Sulpicio, el Viernes, 12 de Octubre, a las 10,30 horas. El Cardenal Daniélou pronunciará la oración fúnebre".

"Le Monde" resumen así, en titulares, su actividad: "Metafísico de la existencia", escritor de "Teatro del escrúpulo"; "un espíritu universal".

Pocos años después, un 9 de Enero de 1976, el Jurado formado por don José $\mathrm{M}^{\mathrm{a}}$. Alfaro, don Gillermo Díaz-Plaza, don Pedro de Lorenzo, don Pedro Rocamora y don José $M^{\text {a }}$ Ruiz- Gallardón, otorgó, por unanimidad, el premio Ensayo Joven, que convoca Editorial Prensa Española, a Carmen Valderrey, autora de la obra titulada: El amor en Gabriel Marcel. 
"Para mí, -declara Carmen Valderrey-, el amor es el tema central de toda la obra de Marcel. Todo su pensamiento filosófico gira en torno al amor, al que se refiere siempre a través de experiencias vitales concretas".

\section{APENDICE I}

Reflexión-evaluación de la tesis doctoral de D. Antonio NATAL ALVAREZ, "La participación en Gabriel MARCEL".

Probablemente la obra de Gabriel Marcel es más autobiográfica que la de otros filósofos; por esta razón, considero oportuna su decisión de iniciar su trabajo abordando unos acertados comentarios y observaciones sobre la vida y el ambiente en que se educó y desenvolvió el filósofo francés. Esta aproximación a la figura de nuestro autor ya nos da testimonio de su proclividad y especial sensibilidad por las cuestiones de ultimidad, que le llevaron en su proceso de maduración intelectual y crecimiento espiritual, a abordar temas tan importantes como la comuncación, el amor, la fidelidad, la ambigüedad de la existencia en el drama moral, el problema del mal ("el mundo estropeado"), la muerte y la transcendencia. Y la profundidad y dificultad de esta temática, en la que vibra como telón de fondo la existencia inobjetivable, le llevará a cultivar todos los medios de sintonía y comunicación, desde la música al teatro.

Vida y filosofía van íntimamente imbricadas en Marcel, por ello será el filósofo siempre en camino, siempre en busca de la verdad, y siempre profundizando en el ser que se la hace presente como misterio. En él, la asistematicidad no tiene nada que ver con el carácter fragmentario y débil del pensamiento postmoderno, sino que es signo de profundidad y de intento de sintonizar con la vida. Lo mismo podría decirse de la condición concreta de su reflexión. La verdad no se puede encontrar fuera de nuestro ser en situación. Cuando pienso comprometo todo mi ser, en esa tarea de profundizar en la situación concreta y total de mi ser humano. Y es en esa tarea donde se topa con el misterio.

La categoría de participación en torno a la cual centra Ud. su investigación sobre la filosofía marceliana es vertebral en su reflexión, y mostrarlo creo que es uno de los méritos de su tesis. Un concepto que con diversas acepciones y matices está presente en una vasta tradición filosófica como también Ud. pone de relieve en su trabajo. La matriz de la que se alimenta su filosofía tiene que ver con aportaciones del platonismo-agustinismo y la filosofía cristiana, 
entre otras. De ahí que su concepto de participación tenga que ver con las ideas de presencia, donación, dependencia, adquisición e imitación...y, en fin, la participación es la vía por la que podemos acceder al misterio del ser.

Marcel, como Ud. nos hace ver en su trabajo, destaca tres niveles de participación: el de la encarnación, que se actualiza por la sensación y la experiencia corporal; el de la comunión, que se actualiza por el amor, la esperanza y la fidelidad; y el de la trascendencia que se actualiza por la exigencia ontológica y la intuición del ser. Aunque, como muy bien indica Ud. y más allá de distinciones teóricas, el tercer nivel está implícito en los dos anteriores, pues si no, no habría progreso ni en el ser, ni en el misterio, y además el amor y la fidelidad, como la esperanza, sólo encuentran su eficacia y significado en la trascendencia.

Mi cuerpo en cuanto no es un puro objeto es realidad misteriosa, donde se me revela una primera participación en el ser: es mi forma de ser en el mundo. Marcel da un paso importante en la historia de la somatología filosófica, aunque deja para otros algunas tareas como "un estudio metafísico frontal de lo que como realidad es el cuerpo humano (qué relación hay entre mi cuerpo y yo, cuando digo "yo soy mi cuerpo"; el alcance físico y metafísico de ese aserto) y una interpretación filosófica de lo que para la ciencia neurofisiológica y psicológica es sentir el cuerpo propio (en otros términos: hacer respecto de la cenestesia lo que respecto de la memoria y el habla había hecho Bergson)" (P. Laín Entralgo. El cuerpo humano. Teoría actual Espasa=Universidad. Madrid, 1989. 254-255).

Otro mérito de su investigación es poner de relieve que el nivel de la participación que se concreta en la comunión-presencia pone de relieve la insuficiencia del materialismo y del intelectualismo abstracto para abordar lo más genuino del misterio humano. Y ello, por la sencilla razón de que el primero no rebasa lo puramente objetivo, y al segundo se le escapa el sentido de lo trágico. Marcel lleva a cabo una metafísica del somos que pone la presencia y la intersubjetividad a la base de la ontología; de ahí la importancia de la comunión con el otro como vía de acceso al ser. El yo existe hacia fuera buscando el encuentro con el otro que posee el secreto de uno mismo. La ciencia positiva no puede ofrecer una respuesta satisfactoria a la realidad existencial que se hace presente en el encuentro personal, y se manifiesta como participación inobjetivable. Es en la intersubjetividad donde me percato de mi participación en el ser y me lo apropio en la comunicación-comunión personales. $\mathrm{Y}$ es ahí donde se supera y desborda la esfera del tener, para adentrarnos en el misterio, en lo que no puede ser resuelto, sino reconocido. Es en la comunión y en el amor donde se hace presente el ser, presencia que se procura perpetuar con la fidelidad y la esperanza. El yo crece en la donación, la fidelidad y la esperanza. 
Estas últimas observaciones nos llevan al tercer nivel de la participación: la exigencia ontológica... Trascender es ir en busca del ser a través de los seres, búsqueda itinerante a través de la intersubjetividad.

La vena agustiniana del pensamiento marceliano que queda de manifiesto en su tesis, me ha ayudado a descubrir un cierto paralelismo entre la ontología del compromiso de Marcel y la filosofía de la acción de Maurice Blondel. Especialmente cuando he leído la nota 191 de su trabajo el bello texto de "Du refus a l'invocation", pág, 198 que reza así : el misterio es interpretado "como la expresión de una voluntad, de una exigencia tan profunda que no se conoce a sí misma, que se traiciona sin cesar forjándose falsas certezas, todo un saber ilusorio, con el que sin embargo no puede contentarse, y que ella misma rompe al prolongar el impulso al cual ha cedido para inventarlas. En este reconocimiento el misterio se trasciende". De manera paralela, cuando Blondel analiza las condiciones de posibilidad del acabamiento de la acción humana (es decir del movimento total de la vida, que incluye el ser del hombre con todo su dinamismo y energía), destacará una inadecuación radical y constante entre la "volonté voulante" (el deseo y la voluntad de desarrollo y realización total del hombre) y la "volonté voulue" (la volicón y objetivos prácticos de la vida humana). La voluntad radical y originaria que nos constituye como causa eficiente se nos revela como superior a las contradicciones e insuficiencias de nuestra vida, a nuestras sucesivas causas finales. De mí a mí mismo hay un abismo, y buscamos de modo itinerante esa última coincidencia con nosotros mismos, en ese trascender hacia nuevos niveles de participación. Ahora bien, Marcel mucho más que Blondel desarrolla una filosofía profunda de la esperanza. La esperanza brota de la exigencia de plenitud que descubrimos en determinadas experiencias (amor, fidelidad...) y que hacen brillar el sentido frente al misterio y la muerte. La esperanza nos ayuda a descodificar signos y huellas que revelan las posibilidades del futuro en el presente, y de la utopía final. El testimonio de Bloch nos hace caer en la cuenta de que la esperanza humana si no descansa y está orientada por una verdadera trascendencia, por un futuro "absoluto" acabará en una mitización de la materia. Frente a ello, la ontología de Marcel acabará siendo una ontología de la invocación y de la posibilidad del encuentro definitivo. Es una ontología que se abre a la revelación. Ahora bien el consentimiento al ser no se nos impone, sino que en ello media nuestra libertad. Y esto nos lleva a una puntualización.

La consecuencia cognoscitiva de la participación es la presencia, y ello en la medida en que la participación implica compromiso más allá de la mera actitud del observador. A esta dimensión epistemológica de la categoría de participación alude Ud. también en su tesis; pero a mi modesto juicio, en la 
medida que aquí se dibuja toda una metodología de lo trascendente, debería, en este punto, haberse explayado más. Es cierto que Ud. señala cómo Marcel aspira a un tipo de experiencia más amplio que el que posibilita una mera relación de dominio sobre la realidad. El conocer que se da en el encuentro no es un simple poder, ni producir, sino un hacerse. La verdad será entonces un acontecimiento que implica la responsabilidad del hombre. Pero el profundizar más en esa cuestión le hubiera llevado a resaltar la filosofía de Marcel como crítica para la práctica, para la vida. Cosa que también le ocurre a la filosofía blondeliana. La filosofía marceliana es una constante invitación a embarcarnos en experiencias del compromiso integral. Me hubiera gustado que en su trabajo hubiera insistido, aunque queda implícito en su discurso, en que la categoría de participación acaba adquiriendo en Marcel no sólo un sentido ontológico, sino también práctico, en cuanto que implica compromi-. so con las experiencias más significativas y valiosas para el hombre. En ellas se nos abre el acceso a lo inobjetivable, a lo metaproblemático; un acceso que más que conquista es apertura, reconocimiento y acogida del ser. Penetramos en el misterio del ser mediante el consentimiento. En Marcel, como en Blondel, las verdades más profundas no son poseídas, sino vividas en la práctica. En alguna medida podemos hablar en ambos autores de un intelectualismo práctico que implica una síntesis de metafísica y ética. A la verdad no se puede llegar sin la mediación de la libertad. Una verdad que en cuanto misteriosa, más que poseerla, nos envuelve y nos posee a nosotros.

Quisiere terminar mi exposición con una pregunta. Teniendo en cuenta que la ontología de Marcel es una ontología del misterio del ser y del don gratuito, ¿no es lógico que nuestro autor hubiese reflexionado y tematizado sobre una categoría tan relevante de la condición humana como el agradecimiento?. Yo diría que si el ser es el lugar de la fidelidad, es también el lugar del agradecimiento. El agradecimiento, como dato psíquico captado introspectivamente, es una respuesta emocional, mediante la cual la persona humana sale, espontánea y significativamente al paso de algo que le ha sucedido, y en lo que capta un sentido. Es además, un fenómeno interpersonal, que implica una relación "yo-tú". Pero el agradecimiento nos abre a una cuestión existencial. Presupone toda una concepción sobre la existencia de la realidad personal, y sobre la eficacia de la benevolencia y el amor. El agradecimiento implica el reconocimineto del mundo interpersonal vivificado por la intención benevolente. La posesión del egoísta es autodestructora; en cambio el agradecimiento por los dones de la vida alienta una capacidad salvadora, como sostiene B. Schwarz, y una capacidad para detectar la gratuidad última de la vida, y el fin del ser. El agradecimiento se nos revela como un nivel de participación en el ser, pues hunde sus raíces en la 
experiencia de la dependencia y la conciencia de lo gratuito; y de él brota la "acción de gracias", que es una forma de acoger y reconocer el ser como Absoluto. Una reflexión que profundizara en el alcance ontológico de este sentimiento y actitud humanos estaría muy en consonancia con la filosofía del compromiso, y de lo concreto de Marcel. Por eso, concretando mi pregunta, la formularía así: ¿En el teatro y las piezas literarias de G. Marcel no hay un abordaje de esta cuestión, que se revela como una ocasión para profundizar en la ontología del compromiso y de la invocación?

Madrid 4 de Diciembre de 1990

FDO. M. Fdez. del Riesgo.

Miembro del Tribunal

DEPARTAMENTO DE ETICA Y SOCIOLOGIA

Universidad Complutense M A D R I D 